\title{
THE TRANSITION TO INVESTMENT- BASED SOCIAL SECURITY WHEN PORTFOLIO RETURNS AND CAPITAL PROFITABILITY ARE UNCERTAIN
}

\author{
Martin Feldstein \\ Elena Ranguelova \\ Andrew Samwick \\ Working Paper 7016 \\ http://www.nber.org/papers/w7016 \\ NATIONAL BUREAU OF ECONOMIC RESEARCH \\ 1050 Massachusetts Avenue \\ Cambridge, MA 02138 \\ March 1999
}

The views expressed in this paper are those of the authors and do not reflect those of the National Bureau of Economic Research.

- 1999 by Martin Feldstein, Elena Ranguelova, and Andrew Samwick. All rights reserved. Short sections of text, not to exceed two paragraphs, may be quoted without explicit permission provided that full credit, including ${ }^{\circledR}$ notice, is given to the source. 
The Transition to Investment-Based Social Security when

Portfolio Returns and Capital Profitability are Uncertain

Martin Feldstein, Elena Ranguelova, and Andrew Samwick

NBER Working Paper No. 7016

March 1999

JEL No. H55

\section{ABSTRACT}

In this paper we study the transition from a pay-as-you-go system of Social Security pensions to an investment-based system in an economy in which portfolio returns and capital profitability are both uncertain. The paper extends earlier studies by Feldstein and Samwick that modeled the transition process in a nonstochastic environment and by Feldstein and Ranguelova that examined the implication of portfolio risk after the transition to an investment-based system has been completed. We analyze transitions to a mixed system that maintains the current 12.4 percent pay-as-you-go tax rate as well as to a system that is completely investment-based. We model intergenerational guarantees and assess the risk of such guarantees to taxpayers.

We find that transitions to either a completely investment-based system or a mixed system that maintains current law benefits can be done with little additional saving in the early years (a maximum of three percent) and substantially lower combinations of taxes and saving deposits in the later years. The extra risk to retirees and/or taxpayers is relatively small, making the investment-based plans preferable to a pure pay-as-you-go system for reasonable degrees of risk aversion.

Martin Feldstein

National Bureau of Economic Research 1050 Massachusetts Avenue Cambridge, MA 02138

msfeldst@nber.org

Elena Ranguelova

National Bureau of Economic Research 1050 Massachusetts Avenue

Cambridge, MA 02138

elena@nber.org
Andrew Samwick Department of Economics Dartmouth College Hanover, NH 03755 and NBER samwick@dartmouth.edu 


\title{
The Transition to Investment-Based Social Security when Portfolio Returns and Capital Profitability are Uncertain
}

\author{
Martin Feldstein, Elena Ranguelova and Andrew Samwick*
}

In this paper we study the transition from a pay-as-you-go system of Social Security pensions to an investment-based system in an economy in which portfolio returns and capital profitability are both uncertain. The paper extends earlier studies by Feldstein and Samwick (1997, 1998a,b) that modeled the transition process in a nonstochastic environment and by Feldstein and Ranguelova (1999) that examined the implication of portfolio risk after the transition to an investment-based system has been completed.

Our analysis shows that contributions to Personal Retirement Accounts (PRAs) that are less than one-third of the projected pay-as-you-go (PAYGO) tax rate can eventually finance annuity payments that exceed the officially projected level of future Social Security pensions with very high probability. The remaining moderate level of retiree risk can be completely eliminated by a government guarantee that can be provided with very little risk to taxpayers.

Although the transition to a pure investment-based system is the natural case to analyze, we also consider a more realistic policy of a transition to a mixed system which in the long run is one-third investment-based and two-thirds pay-as-you-go; this is the stochastic extension of the study by Feldstein and Samwick (1998b). It corresponds to a policy of maintaining the current payroll tax

*Martin Feldstein is professor of economics at Harvard University and president of the National Bureau of Economic Research. Elena Ranguelova is a doctoral candidate at Harvard and a Research Assistant at the NBER. Andrew Samwick is an assistant professor of economics at Dartmouth and a Faculty Research Fellow of the NBER. This paper is part of the NBER project on Risk Aspects of Social Security Reform and was presented at the NBER conference on that subject, January $15-16,1999$. We are grateful to the other participants in the project for comments at the conference and at the pre-conference meeting . 
rate and using investment-based accounts to maintain the current benefit rules instead of raising the tax rate as the population ages.

We begin the paper in section 1 with a summary of the Social Security simulation model that we use and of the statistical parameters incorporated into our simulations of alternative policy rules. Section 2 then sets the stage for the stochastic simulations that are the primary focus of this paper by analyzing a relatively transparent nonstochastic transition from the existing PAYGO system to a fully-funded system with the same projected benefits. We consider four alternative simulations. The basic calculations assume that the funds in the Personal Retirement Accounts earn 5.5 percent, the average postwar real portfolio rate of return on a 60:40 stock-bond portfolio after a 0.4 percent allowance for administrative costs. An alternative simulation (presented in section 2.1) increases this return to approximately 7.5 percent by assuming that the federal government credits to the Personal Retirement Accounts with the incremental federal corporate tax revenue that results from the PRA-induced increase in capital accumulation. Our third simulation (section 2.2) assumes a real rate of return of 3.7 percent, the riskless rate of return available now on Treasury Inflation Protected Securities. The next nonstochastic simulation (section 2.3) assumes that PRA annuity payments partially offset traditional Social Security benefits, with the traditional PAYGO benefits reduced by 90 cents for each dollar of PRA annuity. Finally, we consider (section 2.4) the case in which the PAYGO tax rate remains constant at 12.4 percent and calculate the path of PRA contributions that can maintain the currently projected benefits; this corresponds to a system of two-thirds PAYGO benefits and one third investment-based benefits. 
In section 3 we go from a world of certainty to one in which we recognize the uncertain character of the portfolio return and the volatility of the corporate profits on the incremental PRA capital. The corporate tax collections are important because we use this revenue (in section 5) to finance conditional transfers to retirees that guarantee that retirement income will be at least as large as it would have been with the traditional PAYGO benefits implied by current law. Section 3 specifies the nature of the portfolio uncertainty and the capital productivity uncertainty that we take into account in the remainder of the paper and presents the historical evidence to parametize this stochastic environment.

In section 4 we introduce this uncertainty into the transition process and examine the implications of different PRA saving rates. For each of the PRA saving rates, we simulate 10,000 time series of benefits from the year 2000 to the year 2070. We summarize the implications of the uncertainty by presenting the distribution of these investment-based annuities (initially mixed with declining PAYGO benefits) relative to the PAYGO benefits implied by current law (which we refer to as the "benchmark" benefits) in 2010, 2020, 2030, 2050 and 2070.

The risk that retirees have an unacceptably low level of retirement income can be completely eliminated by a conditional PAYGO payment that fills any gap that may exist between the individual's PRA annuity and the basic benchmark benefit. Of course, this shifts the risk from retirees to concurrent taxpayers, i.e., essentially to employees. Section 5 analyzes the extent of taxpayer risk in such an intergenerational guarantee.

Although we believe that the best way to understand the risks associated with the investment-based plans is to look at the distribution of possible outcomes, we provide explicit 
expected utility function evaluations in section 6 for the basic PRA plans with and without government guarantees.

Sections 4,5 and 6 focus on the transition to a system that is completely investmentbased, i.e., that has completely eliminated any PAYGO component. Analyzing this limiting case provides a useful benchmark because it involves more risk than a mixed system that permanently combines defined benefits financed by government revenue with investment-based PRA annuities. ${ }^{1}$ But as a practical matter, the public policy interest in the United States (as well as in Sweden, Australia and elsewhere) focuses on a mixed system that combines pay-as-you go and investmentbased elements. In section 7 we analyze a mixed system in which the PAYGO component in the long run provides a benefit equal to about two-thirds of the projected "benchmark" benefit. We focus on this level of defined benefit because the PAYGO tax required to pay such a benefit is approximately equal to the current 12.4 percent payroll tax. Since preventing an increase in the payroll tax or a decease in projected benefits is a stated goal of current U.S. public policy, this is a particularly interesting case to consider.

We begin our analysis of this mixed system in section 7 with the assumption that there is no additional guarantee to retirees, i.e., that they are guaranteed to receive the benefits that can be financed with a 12.4 percent payroll tax but bear the risk of the uncertain return associated with the PRA annuities. We then consider the implications of adding a conditional PAYGO benefit of the type considered in section 5 .

\section{The Social Security Simulation Model}

${ }^{1} \mathrm{~A}$ tax-financed defined benefit plan is of course also subject to the political risk that benefits will be reduced by legislation. See McHale (1998). 
Our analysis is based on an extended and updated version of the simple accounting model developed in Feldstein and Samwick (1997, 1998a,b). The model is now calibrated so that with the current Social Security rules it closely approximates the basic time series of benefits, revenues, and trust fund assets predicted in the 1998 Social Security Trustees Report. ${ }^{2}$

The unit of analysis in these simulations is the individual. Benefits for spouses and survivors, as well as disability benefits, are subsumed in the individual benefit projections in a way that satisfies the aggregate annual cost projections of the Social Security Administration. We incorporate the actual current age structure of the population, the Census Bureau projections of future births through 2050, and the projected cohort-specific life tables for individuals born through that year. To reflect the net inflow of immigrants, we scale up the projected population at every age to coincide with the aggregate population projections of the Social Security Administration.

The simulations simplify by assuming that individuals enter the labor force at age 21 and work until they retire at the normal retirement age (or until death if that occurs sooner). Since not everyone in the population actually works during those years, we adjust the labor force participation rate to obtain the number of covered workers in each year specified in the Social Security Administration projections.

We use the historic data for average taxable earnings in covered employment in years before 1998, as given in the 1997 Social Security Annual Statistical Supplement. We follow the

${ }^{2}$ The earlier papers all used the 1995 Social Security Trustees Report and assumed retirement at age 65 retirement. We now assume, in keeping with current law, that the "normal retirement age" is 65 retirement for individuals born before 1941. Those born in 1941 and later retire at age 66 while those born in 1958 and later retire at age 67. 
intermediate assumption in the 1998 Social Security Trustees Report that the average real wage rises at 0.9 percent per year in the future. The movements in the average real wage reflect the changing age structure of the labor force as well as the overall rate of increase in age-specific wages. More specifically, based on the pattern of covered earnings by age as reported in the 1997

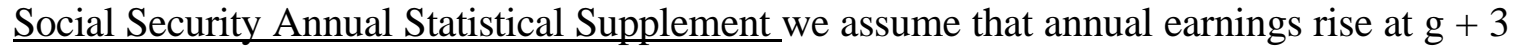

percent for individuals under age 35 , at $\mathrm{g}+1$ percent for individuals between 35 and 45, and at $\mathrm{g}$ minus 1.5 percent for those above 45 years old where the value of $\mathrm{g}$ for each year is chosen to make the overall rise in wages equal to the historic record before 1998 and to the projected 0.9 percent annual rise after 1998.

Each individual employee is required to contribute a fraction of each year's earnings (up to the current ceiling on taxable earnings) to a Personal Retirement Account. ${ }^{3}$ In the non-stochastic simulations with which we begin our analysis, the investments in the Personal Retirement Accounts are assumed to earn a real logarithmic rate of return of 5.5 percent. As we describe in more detail in section 3 , the average real $\log$ rate of return on a fund invested 60 percent in the Standard and Poors portfolio of common stock and 40 percent in a portfolio of corporate bonds during the postwar period through $1995^{4}$ was 5.9 percent. We reduce this return by 0.4 percentage points for administrative costs to produce a net real log rate of return of 5.5 percent. Although this mean log rate of return corresponds to an expected money rate of return of 6.5

${ }^{3}$ The deposit to the PRA could come instead from the individual's employer or from the government, a distinction that we do not pursue here.

${ }^{4}$ Including the more recent period would increase this rate of return. 
percent, ${ }^{5}$ we make the conservative assumption in this section (since we are not dealing with risk explicitly) that the real money rate of return is just 5.5 percent.

At retirement, each individual's PRA balance is used to purchase a variable annuity that invests in the same 60:40 mix of stocks and bonds and therefore has the same 5.5 percent expected real rate of return. ${ }^{6}$ If an individual dies before reaching retirement age, the funds in his PRA are divided among the surviving employees . As we noted above, survivor benefits are implicitly included in the benefit calculations. ${ }^{7}$

The 5.9 percent real log return before administrative expenses is the return earned by "untaxed" portfolio investors after the companies have paid corporate and property taxes to the federal, state and local governments. The full rate of return earned on incremental capital before all taxes during this same period was substantially higher, approximately 8.5 percent (Poterba, 1997). We return below to the implications of this for the taxes collected on incremental capital but not included in the return earned on PRA accounts.

We follow the Social Security Trustees in assuming that the real return on the government bonds in the Social Security trust fund will decline gradually from the current level to a 2.8 percent real interest rate in the future. This is also a conservative assumption (although not a very

${ }^{5}$ With the historic standard deviation of 0.125 and the assumption that the log returns are normally distributed the corresponding "level" or "money" rate of return is 6.5 percent; i.e., if $r$ is the $\log$ rate of return and $\mathrm{E}(\mathrm{r})=0.055$ while the standard deviation of $\mathrm{r}$ is 0.125 , normality implies that $\mathrm{E}\left[\mathrm{e}^{\mathrm{r}}\right]=\mathrm{e}^{\mathrm{E}[\mathrm{r}]+0.5 \sigma 2}=1.065$.

${ }^{6} \mathrm{We}$ describe the nature of variable annuities in detail in section 3 below.

${ }^{7}$ An alternative assumption would be to permit preretirement bequests. Permitting such bequests reduces the survivors' funds available at retirement by about 14 percent. For more on this and related aspects of bequests, see Feldstein and Ranguelova (1998b). 
important one given the relative size of the trust fund) because the Treasury Inflation Protected Securities now provide a real rate of return of 3.7 percent.

Because we are interested in total benefit payments and not in their distribution by income and family type, we base our calculations on average taxable earnings in each year and do not distinguish income levels or family structures. Although we therefore cannot apply the actual Social Security benefit rules, we can calculate average benefits under current Social Security law by attributing an implicit rate of return on the taxes paid by individuals in each birth cohort. The cohort-specific real rates of return of current and future retirees that we apply to these taxes are modifications of earlier estimates by Boskin et al (1987); their estimates, which were for single earner couples, have been adjusted to produce aggregate benefit amounts that coincide with the Trustees' projections of the benefits implied by the current law for future years:

$\begin{array}{lrrrrrrr}\text { Year of birth } & \text { Pre-1915 } & 1915 & 1930 & 1945 & 1960 & 1975 & 1990+ \\ \begin{array}{l}\text { Real Rate of } \\ \text { Return }\end{array} & 7.0 \% & 5.41 \% & 2.42 \% & 1.62 \% & 1.44 \% & 1.29 \% & 1.08 \%\end{array}$

We linearly interpolate between these values to get cohort-specific rates of return for all birth years between 1915 and 1990.

Even with the lower rates of return for younger workers implied by this procedure, the projected benefits cannot be financed by the existing 12.4 percent OASDI tax rate because of the changing age structure of the population. The changing demographics cause the trust fund to be exhausted in the year 2032. Maintaining the projected benefits implied by current law the "benchmark" benefits) would require raising the PAYGO tax from 12.4 percent to nearly 19 percent in the long-run. The rapid aging of the population associated with the baby boom 
generation would raise the tax rate required to fund concurrent benefits to more than 17 percent by the year 2035 .

\section{A Nonstochastic Transition from PAYGO to Investment-based Pensions}

In this section we begin by describing a feasible path from the existing PAYGO taxsupported system to a system that is eventually fully investment-based and receives no tax support. During the transition, this requires a combination of PAYGO taxes and PRA saving deposits. We show that the transition can be achieved with an initial PRA saving deposit of 3 percent of earnings (up to the Social Security taxable maximum), bringing the combination of payroll taxes and PRA saving to 15.4 percent of taxable earnings. This combined amount eventually declines as the PRA annuities reduce the need for the PAYGO benefits. This decline occurs even though the aging of the population would require a rapidly rising payroll tax rate if the pure tax-financed system continued. By the year 2070, the investment-based system can produce the "benchmark" level of benefits with a 4.25 percent PRA saving rate instead of the 18.7 percent payroll tax that would be required in a PAYGO system. This low PRA saving rate could continue for the indefinite future if the basic demographic and economic characteristics of the economy remained unchanged at the levels that they reached in 2070; improvements in mortality after that time would however require increases in the PRA saving rate. .

There are a variety of different possible transitions that can take the system from where it is today to a fully investment-based system. The path that we analyze constrains the total 
retirement benefits in each year -- i.e., the sum of the traditional PAYGO benefit and the PRA annuity -- to be at least as large as the "benchmark" benefits implied for future years by current law. ${ }^{8}$ More specifically, for each cohort, as long as some PAYGO benefits are being paid, the sum of the PAYGO benefit and the PRA annuity are constrained to be exactly equal to the benchmark benefit. When the PAYGO benefit becomes zero, the PRA annuities may exceed the benchmark benefit (because the excess cannot be offset by reducing the PAYGO benefit further.) The trust fund is constrained to remain positive in every year. In order to allow the PAYGO taxes to adjust smoothly, we do not impose requirements on the path of the Trust Fund other than that it remain positive.

The transition is assumed to begin in the year 2000. In that year, all employees from age 21 through age 64 deposit 3 percent of their wages up to the maximum taxable earnings (or have it deposited by employers or the government). The funds in the PRA account receive a 5.5 percent real rate of return. In the next year (2001), those who become 65 and retire receive a very small PRA annuity. ${ }^{9}$ Because of the small PRA annuity, the total retirement benefit of these new retirees ( i.e., the sum of the regular PAYGO benefit and the PRA annuity), can be maintained at its benchmark level with a smaller PAYGO benefit. This permits the payroll tax to be reduced slightly while maintaining the initial path of the trust fund. In each successive year, the

${ }^{8}$ We emphasize that at this point our analysis is nonstochastic. We are really constraining the sum of the PAYGO benefit and the nonstochastic PRA annuity to be at least as large as the benchmark benefit.

${ }^{9}$ As a practical matter, the annuity benefits after just one year of PRA contribution would be so small relative to the administrative costs that it would be more sensible to exclude everyone over some age (say 55) from participating in the transition or to allow them to receive their accumulated PRA balances at retirement as a lump sum with no reduction in their regular Social Security benefits. To simplify the description and analysis, we do not make either modification. 
number of retirees with PRA annuities increases and the average total value of their annuities increases because the retirees have had more years in which to accumulate PRA balances. The required PAYGO benefits and associated taxes therefore decrease over time. This reduction in the PAYGO tax permits the mandatory PRA saving rate to be increased without raising the combined burden of the two.

We can summarize the growth equation for the PRA balance as:

$$
\mathrm{A}(\mathrm{s})=1.055 * \mathrm{~A}(\mathrm{~s}-1)+\alpha(\mathrm{s}) * \mathrm{~W}(\mathrm{~s})-\mathrm{ANN}(\mathrm{s})
$$

where $\mathrm{A}(\mathrm{s})$ is the value of the PRA balance, the 1.055 growth factor reflects the real rate of return $(0.055), \alpha(\mathrm{s})$ is the saving rate at time $\mathrm{s}, \mathrm{W}(\mathrm{s})$ is the wage income at time $\mathrm{s}$ and ANN (s) is the annuity withdrawal at time s.

Table 1 shows the evolution of the transition process. All of the figures in rows 1 through 10 are expressed as percentages of taxable earnings (i.e., earnings up to the maximum amount taxed by Social Security); aggregate taxable earnings in billions of 1998 dollars are shown in row 11.

Row 1 shows the tax rate implied by the current unfunded system. We assume that the Social Security payroll tax rate would remain at its current 12.4 percent level until it becomes necessary to raise the tax rate in order to pay the benchmark level of benefits (shown in row 2 as a percentage of taxable earnings). In the early years, the tax at the current 12.4 percent is more than the amount needed to pay the benchmark benefits and the original trust fund grows. But after a relatively few years, the benefits exceed the revenue raised by a 12.4 percent tax. In 2020 , for example, the benefits are 14.5 percent of taxable earnings, requiring a transfer from the Trust 
Fund balance to make up the 2.1 percent of taxable earnings difference between the benefits and the tax collections. ${ }^{10}$

The trust fund initially grows because payroll tax receipts exceed benefit payments. It continues to grow briefly even when benefits exceed taxes because of the interest earned on its assets and the inflow of the tax on Social Security benefits that the Treasury transfers to the Trust Fund. But even with this supplementary income, the Trust Fund is exhausted by 2032.. This is shown in row 3 . At this point, the tax rate in row 1 is raised to be equal to the benefits in row 2. By 2070, the required tax in the pure PAYGO system is 18.7 percent of taxable earnings; since these earnings are approximately 36 percent of GDP in that year, this corresponds to 7.4 percent of GDP.

Row 4 shows the PRA saving deposits, also expressed as a percentage of taxable earnings (up to the maximum taxable earnings limit). These deposits start at 3.0 percent of taxable earnings for the first seven years (2000 through 2006) and then jump to 4.25 percent of taxable earnings in 2007, the level at which they remain. As successive birth cohorts reach retirement age, they receive PRA annuities. These annuities, shown in Row 5, rise rapidly as the number of retired cohorts increases and as the PRA annuity per cohort rises in recognition of the greater number of years that each successive cohort had been contributing to the PRA accounts. The PRA annuities rise from 1.3 percent of taxable earnings in 2020 to 4.1 percent of taxable earnings in 2030, 13.0 percent of taxable earnings in 2050 and 19.8 percent of taxable earnings in 2070.

\footnotetext{
${ }^{10}$ The transfer from the trust fund requires the trust fund to sell bonds to the public, increasing the unified budget deficit or reducing the unified budget surplus.
} 
The PAYGO benefits are reduced dollar for dollar in response to the rising PRA annuities in a way that keeps the sum equal to the original benchmark benefits as long as PAYGO benefits are positive. This permits the PAYGO tax rate to be reduced. The path of the PAYGO tax during the transition is shown in Row 6. The initial 12.4 percent tax rate is reduced in 2010 to 11.15 percent and remains at this level until 2039. It is then reduced by 0.5 percent of taxable earnings each year until it reaches 5.15 percent of taxable earnings in 2051. After that, it declines at one percent of taxable earnings per year until it is 0.15 percent of taxable earnings in 2056 and zero

Table 1

$\underline{\text { Transition Path of Tax Rates, PRA Contributions and Annuities }}$

(All figures are expressed as percentage of taxable earnings.)

\begin{tabular}{|c|c|c|c|c|c|c|}
\hline & $\underline{2000}$ & $\underline{2010}$ & $\underline{2020}$ & $\underline{2030}$ & $\underline{2050}$ & $\underline{2070}$ \\
\hline 1. Tax Rate with PAYGO System & 12.40 & 12.40 & 12.40 & 12.40 & 17.29 & 18.70 \\
\hline 2. Benchmark Benefits & 10.96 & 11.72 & 14.50 & 17.14 & 17.16 & 18.55 \\
\hline 3. Trust Fund with PAYGO System & 25.46 & 40.95 & 39.57 & 6.66 & 0.00 & 0.00 \\
\hline 4. PRA Saving Deposits & 3.00 & 4.25 & 4.25 & 4.25 & 4.25 & 4.25 \\
\hline 5. PRA Annuities & 0.00 & 0.20 & 1.35 & 4.05 & 13.02 & 19.80 \\
\hline $\begin{array}{l}\text { 6. PAYGO Tax Rate in Transition } \\
0.00\end{array}$ & & 12.40 & 11.15 & 11.15 & 11.15 & 5.65 \\
\hline 7. PAYGO Tax Rate + PRA Saving Rate & 15.40 & 15.40 & 15.40 & 15.40 & 9.90 & 4.25 \\
\hline 8. PAYGO Benefits + PRA Annuities & 10.96 & 11.72 & 14.50 & 17.14 & 17.51 & 20.00 \\
\hline 9. Trust Fund & 25.46 & 36.55 & 28.49 & 8.13 & 18.88 & 3.03 \\
\hline
\end{tabular}


10. PRA Asset Balances

11. Covered earnings in Billions of 1998 Dollars 7634.87
3.00

44.75

111.09

191.47

329.71

367.77

3528.24

4096.18

4610.91

5077.32

6287.71 
thereafter. After that, the income of the Trust Fund is sufficient to finance the remaining PAYGO obligations.

The combined PAYGO tax and the PRA deposit rate is shown in row 7. In the beginning of the transition, the combination rises from the current 12.4 percent PAYGO tax to 15.4 percent. It remains at this level in 2007 when the PAYGO tax is cut to 11.15 percent at the same time that the PRA deposit rate increases from 3.0 percent to 4.25 percent. Since the PRA saving rate remains permanently at 4.25 percent, the combined total begins to fall in 2040 when the PAYGOtax rate begins to decline. In 2045 the PAYGO tax is down to 8.15 percent, bringing the combined total back down to 12.40 percent of taxable earnings, the initial PAYGO tax. In contrast, the pure PAYGO system would require a 17.27 percent tax in that year to support the same level of benefits. While the pure PAYGO tax rate would rise after that year, the combined PAYGO and PRA rate falls from 12.4 percent in 2045 to 9.9 percent in 2050 and to 4.25 percent in 2057 and all subsequent years.

After the PAYGO tax rate has been reduced to zero (in 2057), further increases in the PRA annuities are reflected in a higher level of total benefits (the sum of the PAYGO benefit and the PRA annuity, shown in row 8.) By 2070 the ratio of the PRA benefit to the benchmark benefit (shown in row 2) is 1.07.

The accumulated PRA assets are shown in Row 9. This rises from 45 percent of taxable earnings in 2010 to 3.7 times taxable earnings in the year 2070. As a percentage of GDP, this represents a rise from about 18 percent of GDP in 2010 to about 1.5 times GDP in 2070. Since 
the capital stock is about three times GDP, this can also be expressed as a 6 percent rise in the capital stock after 10 years and a 50 percent rise in the capital stock after 70 years. ${ }^{11}$

For information, we show in row 10 the level of the government Social Security Trust Fund. This could of course be eliminated completely once the PAYGO benefits become zero.

Finally, row 11 shows the covered taxable earnings, expressed in 1998 dollars.

\subsection{Incremental Corporate Tax Revenue and Supplemental Saving Deposits}

The calculations summarized in Table 1 assume that the real rate of return on PRA saving is 5.5 percent. Although this has been the historic mean log return to "nontaxable" portfolio investors on the 60:40 portfolio investment (net of the assumed 0.40 percentage point administrative cost), it is substantially less than the real pretax marginal rate of return on additions to the corporate capital stock. The primary reason for the difference is the taxes collected by federal, state and local governments.

The national income and product account data analyzed by Poterba (1997) imply that during the years 1959 to 1996 the real pretax marginal product of capital in the nonfinancial corporate sector was 8.5 percent. Of this, Poterba estimates that the federal government

\footnotetext{
${ }^{11}$ The large long run rise in the capital stock would have general equilibrium effects on the marginal product of capital and on real wages that we do not take into account here. A CobbDouglas technology, an unchanged path of human capital, the absence of international capital flows, and a 25 percent capital share implies that the marginal product of capital would decline in the very long-run by about 25 percent (e.g., from $8.5 \%$ to $6.4 \%$ ). This decline would be offset to the extent that the lower marginal tax rates induced a higher labor supply and the lower interest rate induced a greater investment in human capital. We do not pursue such general equilibrium effects here.
} 
collected 2.2 percentage points in corporate profit taxes (an effective tax rate of 26 percent $^{12}$ ). State and local governments took an additional 0.3 percentage points in profits taxes and 0.9 percentage points in property taxes. These taxes imply that the net return to portfolio investors during those years would be 5.1 percent. Although this is substantially less than the return to the 60:40 stock-bond portfolio that we discussed above, it is the same as the mean level return of that stock-bond portfolio for the years of the Poterba sample. This suggests that the Poterba sample of years may have had a lower than normal rate of profitability for the postwar period as a whole. We will nevertheless make the conservative estimate of a federal corporate tax collection equal to 2.0 percent of the incremental capital stock.

There are three potential uses of this additional corporate tax revenue. The most direct is to use it to finance a portion of the PRA saving deposits instead of requiring individuals and/or their employers to pay for this or using other government revenue for this purpose. A second alternative is to supplement the 5.5 percent return, raising it to $7.5 \%$. Finally, in section 5 , after the stochastic simulations have been introduced, we show how the additional corporate tax revenue can be used to finance a benefit guarantee to retirees.

Since we take the incremental corporate tax revenue to be two percent of the incremental corporate stock, we must estimate the increase in the national corporate capital stock that results from the PRAs. In principle, this requires looking beyond the PRA program itself to see how the PRA accounts might alter other private saving, something that would change over time. In the

${ }^{12} \mathrm{~A} 26$ percent effective tax rate is substantially less than the statutory corporate profits tax rate which is now 35 percent and which has had a higher average during the sample years. The difference reflects the deduction of state and local property and income taxes in the calculation of federal tax liability and the combination of depreciation allowances and interest deductions. 
early years of the PRA program, disposable income would decline, giving individuals an incentive to reduce other saving in order to maintain a more level time path of consumption. The quantitative importance of this is however likely to be small since the vast majority of Americans have too little in financial assets to do any such offsetting reductions. Moreover, some individuals might be stimulated by participating in the PRA program to recognize the value of saving and therefore to increase their other saving. As the PRA system matures, the reduction in the combined total of the payroll tax and the PRA deposits (shown as the difference between rows 1 and 7 of Table 1) would raise disposable income during working years with virtually no change in retirement incomes, inducing individuals to save more during their working years in order to smooth consumption over time. That increase in saving would make national saving rise. In our calculations, we ignore such possible changes in individual consumption and saving and assume that the nation's capital stock increases by the net inflows to the PRA accounts plus the PRA capital income (interest, dividends and retained earnings) of those accounts.

In the current nonstochastic model, this growth of the incremental capital stock should be well measured by the market value of the PRA assets. ${ }^{13}$ The aggregate value of the assets in the PRA accounts grows initially because the PRA deposits exceed the annuity withdrawals. But after the early years, the primary source of the increase in the PRA asset value is the 5.5 percent return that is earned on the net assets in the PRA accounts and the annuity payments eventually exceed the savings deposits. This is shown in rows 4 and 5 of Table 1.

${ }^{13}$ In the next section, where we explicitly consider fluctuations in asset market values, we will distinguish between the two and will model the evolution of the incremental capital stock explicitly. 
Using 2 percent of the incremental capital stock (i.e., the assumed additional federal corporate tax receipts) to finance a portion of the PRA saving deposits, instead of requiring individuals and/or their employers to pay for this or using other government revenue for this purpose, has a small effect in the early years but a very substantial effect in the more distant future. ${ }^{14}$ In 2010, the incremental corporate tax revenue would be about $\$ 36$ billion (at 1998 prices) or 0.9 percent of taxable earnings, permitting the additional PRA deposits to be reduced from 4.25 percent of taxable earnings to 3.35 percent of taxable earnings. ${ }^{15}$ But by 2030 the incremental corporate tax revenue would be $3.83 \%$ of taxable earnings and would permit reducing the additional PRA deposit to 0.42 percent of taxable earnings, bringing the total from 15.5 percent of taxable earnings to 11.67 percent of taxable earnings, less than the current pure PAYGO tax rate of 12.4 cent. In 2050, 2 percent of the incremental capital stock would be $6.60 \%$ of taxable earnings, more than enough to pay for all of the $4.25 \%$ PRA deposit and to permit the PAYGO tax to be reduced from 5.65 percent to 4.30 percent. Eventually, in 2070, the incremental revenue would be 7.35 percent of taxable earnings; since there is no longer a PAYGO tax at that time and the PRA deposits are only 4.25 percent of taxable earnings, the extra corporate tax revenue would finance the PRA program and leave 3.1 percent of taxable earnings for other uses.

We now consider the implication of an alternative use of these incremental corporate tax funds: using this additional federal corporate tax collection to supplement the return earned in the Personal Retirement Accounts. More specifically, we will assume that this additional corporate tax revenue is divided among the PRAs accounts in proportion to the asset value of those accounts.

\footnotetext{
${ }^{14}$ This is the approach used by Feldstein and Samwick (1998b).

${ }^{15}$ These figures and others cited in this paragraph can be derived from row 10 of Table 1.
} 
This raises the return on the assets in the PRA accounts from 5.5 percent to 7.5 percent, changing equation 2.1 to:

$$
\text { (2.2) } \quad \mathrm{A}(\mathrm{s})=1.075 * \mathrm{~A}(\mathrm{~s}-1)+\alpha(\mathrm{s}) * \mathrm{~W}(\mathrm{~s})-\mathrm{ANN}(\mathrm{s})
$$

where $\mathrm{A}(\mathrm{s})$ is the value of the PRA balance, the 1.075 growth factor reflects the real rate of return, $\alpha(\mathrm{s})$ is the PRA saving rate at time $\mathrm{s}, \mathrm{W}(\mathrm{s})$ is the wage income at time s and ANN (s) is the annuity withdrawal at time s.

The higher rate of return permits lower PRA saving rates to be consistent with the requirements that the benchmark benefits be financed, the Trust Fund remain solvent, and the PRA annuities eventually fully replace PAYGO benefits. Our calculations show that this can be satisfied with a constant 2.1 percent PRA deposit rate. The PAYGO tax drops from $12.40 \%$ to $11.40 \%$ in 2020 and stays at that level until 2028, when it drops by $1.1 \%$ to $10.3 \%$. In 2028 the sum of the PAYGO tax rate and the PRA deposit rate is back to $12.40 \%$. The PAYGO tax rate stays at 10.3 percent until 2040, when it gets phased out at a rate of $0.5 \%$ per year. The PAYGO tax is therefore gone by 2060 and the only cost is the 2.1 percent PRA deposit.

These results are summarized in Table 2 which follows the same format as Table 1 . The first three rows of Table 2 are the same as in Table 1. The PRA saving deposits in row 4 are substantially smaller but the PRA annuities are larger after 2045. The combined PAYGO tax and PRA deposits is lower than 12.4 percent.

\subsection{Implications of a Risk Free Investment}


Since we are ignoring risk at this point in our analysis, it is sensible to consider what a transition path might look like if the rate of return is reduced from the 5.5 percent mean real return on a debt-equity portfolio to the real return available on inflation protected U.S. Treasury bonds, i.e., the Treasury Inflation Protected Securities (TIPS). Such investments have no default risk and no risk of inflation erosion. For an investor who holds them to maturity, there is no market risk due to interest rate fluctuations. Since the TIPS currently have a 3.7 percent real yield at a variety of maturities, we use that rate of return in these risk free return calculations.

Achieving a transition to a completely investment-based system with this lower real rate of return requires starting with a higher PRA saving rate than the one used in the simulations with 5.5 percent and 7.5 percent real rates of return. A feasible solution begins with a PRA saving rate of 5.0 percent (instead of the 3.0 percent in Table 1) and gradually increase this to 8.0 percent while reducing the PAYGO tax rate. The specific path is summarized in Table 3 which follows the same format as Tables 1 and 2 .

The PAYGO tax rate declines from the initial 12.4 percent to 11.4 percent in 2010, 10.40 percent in 2030, 9.40 percent in 2050, and zero after 2061. The combined PAYGO tax rate and PRA Saving Deposit (row 7) therefore remains at 17.4 percent until after 2050 but declines to 8.00 percent permanently by 2070 . 
Table 2

Transition Path with Supplementary Savings Deposits*

(All figures are expressed as percentage of taxable earnings.)

$\begin{array}{lcccccc} & \underline{2000} & \underline{2010} & \underline{2020} & \underline{2030} & \underline{2050} & \underline{2070} \\ & & & & & & \\ \text { 1. Tax Rate with PAYGO System } & 12.40 & 12.40 & 12.40 & 12.40 & 17.29 & 18.70 \\ \text { 2. Benchmark Benefits } & 10.96 & 11.72 & 14.50 & 17.14 & 17.16 & 18.55 \\ \text { 3. Trust Fund with PAYGO System } & 25.46 & 40.95 & 39.57 & 6.66 & 0.00 & 0.00 \\ \text { 4. PRA Saving Deposits } & 2.10 & 2.10 & 2.10 & 2.10 & 2.10 & 2.10 \\ \text { 5. PRA Annuities } & 0.00 & 0.16 & 1.11 & 3.58 & 13.41 & 20.06 \\ \text { 6. PAYGO Tax Rate in Transition } & 12.40 & 12.40 & 11.40 & 10.30 & 4.80 & 0.00 \\ \text { 7. PAYGO Tax Rate + PRA Saving Rate } & 14.50 & 14.50 & 13.50 & 12.40 & 6.90 & 2.10 \\ \text { 8. PAYGO Benefits + PRA Annuities } & 10.96 & 11.72 & 14.50 & 17.14 & 17.95 & 20.23 \\ \text { 9. Trust Fund } & 25.46 & 41.52 & 45.42 & 23.67 & 15.36 & 6.60 \\ \text { 10. PRA Asset Balances } & 2.10 & 30.53 & 76.29 & 140.10 & 264.68 & 297.42 \\ \text { 11. Covered earnings in } & & & & & & \end{array}$

* The supplementary saving deposits are equal to 2.0 percent of the PRA Asset Balances and effectively raise the rate of return from 5.5 percent to 7.5 percent. 
Thus even with a risk-free rate of return of only 3.7 percent, the investment-based system can support the benchmark level of benefits with a long-run saving rate of only 8.0 percent instead of the PAYGO tax rate of 18.7 percent. Even in this least favorable case of maximum risk aversion, the investment-based approach permits using a five percent higher saving-plus-tax rate in the transition years in order to reduce the equilibrium saving-plus-tax-rate permanently by more than 10 percent of covered earnings.

An individual who is prepared to accept some risk of lower benefits in retirement can achieve the same expected benefits with a substantially lower long-term saving rate. Before examining that possibility, we consider the implications of a partial integration of the PRA annuities and Social Security benefits.

\subsection{Partial Integration of PRA Annuities and Social Security Benefits}

In the transitions shown in tables 1, 2 and 3 the traditional PAYGO Social Security benefits were effectively reduced by a dollar for every dollar of PRA annuity that individuals

received. An alternative integration rule for integrating Social Security PAYGO benefits and the PRA annuities that might be preferred when uncertainty is recognized (and therefore when individuals have some choice about their investments) reduces regular Social Security benefits by 
Table 3

Transition Path with 3.7 Percent Risk Free Rate of Return*

(All figures are expressed as percentage of taxable earnings.)

\begin{tabular}{|c|c|c|c|c|c|c|}
\hline & $\underline{2000}$ & $\underline{2010}$ & $\underline{2020}$ & $\underline{2030}$ & $\underline{2050}$ & $\underline{2070}$ \\
\hline 1. Tax Rate with PAYGO System & 12.40 & 12.40 & 12.40 & 12.40 & 17.29 & 18.70 \\
\hline 2. Benchmark Benefits & 10.96 & 11.72 & 14.50 & 17.14 & 17.16 & 18.55 \\
\hline 3. Trust Fund with PAYGO System & 25.46 & 40.95 & 39.57 & 6.66 & 0.00 & 0.00 \\
\hline 4. PRA Saving Deposits & 5.00 & 6.00 & 6.00 & 7.00 & 8.00 & 8.00 \\
\hline 5. PRA Annuities & 0.00 & 0.25 & 1.51 & 4.05 & 11.08 & 17.42 \\
\hline $\begin{array}{l}\text { 6. PAYGO Tax Rate in Transition } \\
0.00\end{array}$ & & 12.40 & 11.40 & 11.40 & 10.40 & 9.40 \\
\hline 7. PAYGO Tax Rate + PRA Saving Rate & 17.40 & 17.40 & 17.40 & 17.40 & 17.40 & 8.00 \\
\hline 8. PAYGO Benefits + PRA Annuities & 10.96 & 11.72 & 14.50 & 17.14 & 17.16 & 18.61 \\
\hline 9. Trust Fund & 25.46 & 40.87 & 37.49 & 21.87 & 18.79 & 22.43 \\
\hline 10. PRA Asset Balances & 5.00 & 61.22 & 136.28 & 215.06 & 366.24 & 440.32 \\
\hline \multicolumn{7}{|l|}{ 11. Covered earnings in } \\
\hline Billions of 1998 Dollars & 3528.24 & 4096.18 & 4610.91 & 5077.32 & 6287.71 & 7634.87 \\
\hline
\end{tabular}

*The 3.7 percent real rate of return implicit in these calculations is the present yield on Treasury Inflation Protected Securities of varying maturities. 
less than one dollar for every dollar of annuity income. ${ }^{16}$ When the PRA annuities are uncertain, this partial integration reduces the risk to retirees by making the PAYGO benefits more when the PRA annuities are smaller. ${ }^{17}$

We now study such a partial integration plan in the nonstochastic context to provide a framework for understanding the subsequent stochastic results. We use a 90 percent integration rule that provides that the regular PAYGO benefits are reduced by 90 cents for every dollar of PRA annuity. ${ }^{18}$ We again assume a 5.5 percent rate of return and make no allowance for the possible use of the incremental corporate tax revenue. This option provides substantially higher benefits to retirees and therefore reduces the cost of the PAYGO program by less than the analysis shown in Table 1.

${ }^{16}$ Alternatively, the simulations that we have already discussed could be thought of as providing a fixed level of PAYGO benefits in each year with individuals receiving the uncertain PRA annuities as a supplement with the PAYGO benefit levels selected so that with the expected return the two provide the benchmark benefits.

${ }^{17}$ Feldstein and Samwick (1998b) analyzed a plan in which the PRA contributions equal to 2 percent of taxable earnings are financed by the government (rather than by mandatory saving) and each dollar of annuity that retirees receive reduces their regular Social Security benefits by 75 cents. That analysis showed that PRA deposits equal to two percent of covered earnings and 5.5 percent real rate of return would permit the projected level of benchmark benefits to be paid indefinitely with no increase in the existing 12.4 percent PAYGO taxable earnings tax. Moreover, the corporate tax revenue generated by the incremental capital would be enough by the year 2030 to finance fully the PRA deposits equal to 2 percent of covered earnings.

${ }^{18}$ Alternatively, this can be interpreted as reducing the PRA annuity by 90 percent as long as that reduction does not exceed the value of the PAYGO benefits. 
With the assumed 5.5 percent real rate of return, it is therefore necessary to have higher PRA deposits than with the dollar-for-dollar integration rule of Table 1. There are again many possibilities. We constrain the choice by imposing the requirement that the combined PAYGO tax and PRA deposit not rise by more than three percent of taxable earnings, i.e., that the combined amount not exceed 15.4 percent of taxable earnings. With that condition, a feasible path begins with a 3 percent PRA deposit from 2000 to 2019, rising to four percent from 2020 to 2032, and then to 5 percent after that. Table 4 presents the transition paths of the basic variables for this case.

\subsection{A Mixed System with a Permanent $12.4 \%$ Earnings Tax and a 75\% Integration Rule}

We now consider the more realistic case of a mixed system that provides retirement income through a combination of PAYGO tax financed benefits and individual investment-based annuities. We fix the PAYGO tax rate at its current 12.4 percent level and leave it there for all future years.

We also have a constant rate of saving in the PRA accounts equal to 2.3 percent of covered earnings.We follow a 75 percent integration rule in which the traditional Social Security benefits in each year are reduced by 75 percent of the PRA annuity. Stated differently, 75 percent of the PRA annuity is paid to the Social Security Administration to help defray the cost of the Social Security annuities. The combination of the (net) PAYGO benefit and the (net) PRA annuity is therefore equal to the benchmark Social Security benefit plus 25 percent of the PRA annuity. The balance in the Social Security Trust Fund adjusts to reflect the difference between the benefits paid and the combination of the 12.4 percent payroll tax revenue and the 75 percent of the PRA annuity. 
Table 4

Transition Path with 90 Percent Integration Rule*

(All figures are expressed as percentage of taxable earnings.)

$\begin{array}{lccccccc} & \underline{2000} & \underline{2010} & \underline{2020} & \underline{2030} & \underline{2050} & \underline{2070} \\ \text { 1. Tax Rate with PAYGO System } & 12.40 & 12.40 & 12.40 & 12.40 & 17.29 & 18.70 \\ \text { 2. Benchmark Benefits } & 10.96 & 11.72 & 14.50 & 17.14 & 17.16 & 18.55 \\ \text { 3. Trust Fund with PAYGO System } & 25.46 & 40.95 & 39.57 & 6.66 & 0.00 & 0.00 \\ \text { 4. PRA Saving Deposits } & 3.00 & 3.00 & 4.00 & 4.00 & 5.00 & 5.00 \\ & & & & & & & \\ \text { 5. PRA Annuities } & 0.00 & 0.19 & 1.16 & 3.4 & 11.30 & 19.66\end{array}$

6. PAYGO Tax Rate in Transition 0.00

$\begin{array}{lllll}12.40 & 12.40 & 11.40 & 11.40 & 8.90\end{array}$

7. PAYGO Tax Rate + PRA Saving Rate

$\begin{array}{llllll}15.40 & 15.40 & 15.40 & 15.40 & 13.90 & 5.00\end{array}$

8. PAYGO Benefits + PRA Annuities

11.74

14.62

17.49

18.29

20.92

9. Trust Fund

25.46

41.55

45.28

24.16

12.92

12.77

10. PRA Asset Balances

$3.00 \quad 39.48$

$89.85 \quad 160.56 \quad 315.31$

405.71

11. Covered earnings in

Billions of 1998 Dollars

$\begin{array}{llllll}3528.24 & 4096.18 & 4610.91 & 5077.32 & 6287.71 & 7634.87\end{array}$

*The 90 percent integration rule provides that each individual receives a PAYGO benefit equal to the benchmark level minus 90 percent of the individual's PRA annuity. 
These results are shown in the standard format in Table 5. Rows 4 and 5 describe the simple combination of the 12.4 percent PAYGO tax and the 2.3 percent PRA deposit rate. Row 6 shows the gross PRA annuities (i.e., before any allowance for the 75 percent integration effect) that would result from the 2.3 percent PRA deposits. These annuities are less than one percent of covered earnings in 2020 but rise to 2.54 percent in $2030,7.65$ percent in 2050 and 10.75 percent in 2070 .

Individuals receive the sum of their promised benchmark benefits (row 2) and 25 percent of these gross PRA annuities. Equivalently, the individuals receive the entire gross PRA annuities plus the benchmark benefits reduced by 75 percent of those annuities. The combined sum is shown in row 8 . In the early years of the transition the combined total is only slightly greater than the benchmark benefits. But by 2050 the benefits are increased by nearly two percent of earnings, an 11 percent rise in total benefits. By 2070 the combined benefits are equal to 21.24 percent of earnings, or 15 percent higher than they would be under the pure PAYGO system.

The partially investment-based character of this system makes the benefit increase possible despite the fact that the combination of the PAYGO tax rate and the PRA saving rate is limited to 14.7 percent instead of rising to the 18.70 percent rate required in the pure PAYGO system.

The Social Security Trust Fund (row 9) remains positive throughout the 70 year simulation period. The value of the trust fund remains higher because the PRA benefits reduce the need for PAYGO benefits. Although the Trust Fund drops to a low of less than one percent of covered earnings in 2046, it then recovers to 3.13 percent of covered earnings in 2050 and 42.74 percent of covered earnings in 2070 . 


\section{Uncertain Returns to Portfolio Investments and to the Incremental Capital_Stock}

A primary concern in any analysis of the desirability of shifting from a tax-financed defined benefit plan to an investment-based defined contribution plan is the inherent uncertainty of the returns earned on portfolio investments. This uncertainty affects the accumulation during the preretirement years as well as the return on the variable annuity that we assume is used in the postretirement years.

In addition to this portfolio uncertainty, there is also uncertainty about the amount of corporate tax revenue that the government would collect on the incremental capital that results from the Personal Retirement Account saving. This is particularly relevant if that tax revenue is used to supplement or finance contributions to Personal Retirement Accounts or to finance a government guarantee of minimum benefits.

This section describes the stochastic properties of these two sources of uncertainty that we incorporate in the analysis that follows in the rest of the paper. There are of course other sources of uncertainty that affect both tax-financed plans and investment-based plans that we do not explore here, including uncertain mortality rates ${ }^{19}$, birth and immigration rates, and shifts in employment and wage rates.

\footnotetext{
${ }^{19} \mathrm{We}$ use expected mortality rates in our calculations but do not take into account the uncertainty or instability of those rates.
} 
Table 5

Transition Path with Mixed PAYGO and Investment-Based System:

12.4 Percent PAYGO Tax, 2.3 Percent PRA Deposits, and 75 Percent Benefit Integration

(All figures are expressed as percentage of taxable earnings.)

\begin{tabular}{|c|c|c|c|c|c|c|c|}
\hline & 2000 & 2010 & 2020 & 2030 & 2050 & 2070 & \\
\hline 1. Tax Rate with PAYGO & 12.40 & 12.40 & 12.40 & 12.40 & 17.29 & 18.70 & \\
\hline 2. Benchmark Benefits & 10.96 & 11.72 & 14.50 & 17.14 & 17.16 & 18.55 & \\
\hline 3. Trust Fund with PAYGO System & 25.46 & 40.95 & 39.57 & 6.66 & 0.00 & 0.00 & \\
\hline 4. PRA Saving Deposits & 2.30 & 2.30 & 2.30 & 2.30 & 2.30 & 2.30 & \\
\hline 5. PRA Annuities (Gross) & 0.00 & 0.14 & 0.89 & 2.54 & 7.65 & 10.75 & \\
\hline 6. PAYGO Tax Rate in Transition & 12.40 & 12.40 & 12.40 & 12.40 & 12.40 & 12.40 & 12.40 \\
\hline 7. PAYGO Tax Rate + PRA Saving Rate & 14.70 & 14.70 & 14.70 & 14.70 & 14.70 & 14.70 & \\
\hline 8. PAYGO Benefits + PRA Annuities & 10.96 & 11.76 & 14.72 & 17.78 & 19.07 & 21.24 & \\
\hline 9. Trust Fund & 25.45 & 41.33 & 43.85 & 25.31 & 3.13 & 42.74 & \\
\hline 10. PRA Asset Balances & 2.30 & 30.27 & 63.3 & 112.82 & 183.58 & 199.92 & \\
\hline \multicolumn{8}{|l|}{ 11. Covered earnings } \\
\hline in Billions of 1998 Dollars & 3528.24 & 4096.18 & 4610.91 & 5077.32 & 6287.71 & 7634.87 & \\
\hline
\end{tabular}




\subsection{The uncertain investment return ${ }^{20}$}

Our analysis assumes that each individual deposits a specified fraction of each year's taxable wage income in a Personal Retirement Account and that the funds in that account are invested in a portfolio that is continually rebalanced to maintain 60 percent equities and 40 percent debt, approximately the debt-equity ratio of U.S. corporations. At retirement, these accumulated assets are used to finance a variable annuity that we assume is invested in the same stock-bond mixture as the PRA balances were during the preretirement years.

Before looking at the stochastic specification of the portfolio returns, we describe the nature of the variable annuity. The annuity benefit that is paid in the first year of retirement (at age 67 (on an annuity purchased at age 66) reflects the PRA assets at the beginning of the individual's $66^{\text {th }}$ year, the expected mortality rates at all future ages, and the assumption that the future return will be equal to the constant expected rate of return. The annual benefits are then adjusted each year to reflect changes in the value of the annuity account that result from the difference between the realized and expected rate of return.

More specifically, after one year, the size of the variable annuity payment is increased or decreased from the initial value in proportion to the change in the market value of the PRA annuity assets relative to the market value that would have prevailed if the expected rate of return had

\footnotetext{
${ }^{20}$ This analysis draws on Feldstein and Ranguelova (1999).
} 
actually occurred. A similar revision of the annual annuity payment occurs in each subsequent year.

To derive the explicit value of the variable annuity, consider the individuals in a particular birth cohort. Let the time index coincide with the age of the cohort so that $\mathrm{N}_{\mathrm{t}}$ is the number of individuals alive at age t. Let $\mathrm{A}_{66}$ be the value of the PRA assets at the beginning of the $66^{\text {th }}$ year and let $\mathrm{R}$ be the expected annual real rate of return on the portfolio of assets used to finance the retirement annuity. The first annuity benefit is paid at the beginning of the individual's $67^{\text {th }}$ year and annually thereafter. The cost at age 66 of a fixed real annuity of $\$ 1$ for life (i.e., an annuity that starts with $\$ 1$ and grows in proportion to the level of consumer prices) is the actuarial present value (APV) of that dollar with discount rate R:

$$
\operatorname{APV}=\sum_{t=67}^{t=100}\left(N_{t} / N_{66}\right)(1+R)^{-(t-66)}
$$

where we assume that all individuals alive at age 99 die at the end of the $100^{\text {th }}$ year.

Since the PRA account has assets equal to $\mathrm{A}_{66}$ when the annuity is established, the annuity payment that the individual would receive in the $67^{\text {th }}$ year is $a_{67}=A_{66} / A P V$ if the expected return of $\mathrm{R}$ is actually realized in the $66^{\text {th }}$ year. More generally, if the expected return of $\mathrm{R}$ is realized in every future year, the individual would continue to receive that same annuity and the accumulated assets at age 66 of all members of that birth cohort would be exhausted when the last member of the cohort dies at age 100 .

In practice, of course, the actual rate of return varies from year to year. The annuity payments are adjusted in proportion to the annual changes in the asset value in such a way that the 
birth cohort's accumulated fund is still exhausted over the 34 year retirement period. If $R_{t}$ is the actual rate of increase of the asset value during year $t$, the asset value at the beginning of the cohort's $67^{\text {th }}$ year is $A_{67}=A_{66}\left(1+R_{66}\right)$. The annuity paid in that year is therefore $a_{67}=\left(A_{66} / A P V\right)\left(1+R_{66}\right) /(1+R)$. Similarly the annuity at age 68 reflects the changes in the market value of the assets during the $66^{\text {th }}$ and $67^{\text {th }}$ years: $a_{68}=a_{67}\left(1+R_{67}\right) /(1+R)=\left(A_{66} / A P V\right)$ $\left[\left(1+\mathrm{R}_{67}\right) /(1+\mathrm{R})\right]\left[\left(1+\mathrm{R}_{66}\right) /(1+\mathrm{R})\right]$. The last payment to those who are 100 years old is $\mathrm{a}_{100}=\mathrm{a}_{99}\left(1+\mathrm{R}_{99}\right) /(1+\mathrm{R})$. Note that if the rate of return in each period is equal to the expected rate of return the annuity remains constant at $a_{67}$.

Consider now the stochastic specification of the return, $R_{t}$, on the PRA assets and on the assets used to fund the variable annuity. Recall that the portfolio is 60 percent equity and 40 percent debt. We use the S\&P 500 index and a Salomon Brothers corporate bond index as proxies for the stock and bond investments. Both indices are assumed to follow a geometric random walk with drift. This implies that the log returns for each type of asset are serially independent and identically distributed with given mean and variance. Thus if $\mathrm{p}_{\mathrm{e}}(\mathrm{s})$ and $\mathrm{p}_{\mathrm{b}}(\mathrm{s})$ are the $\log$ levels of the equity and bond indices at time s, we assume

$$
p_{e}(s)=p_{e}(s-1)+\mu_{e}+u_{e}(s)
$$

and

$$
\mathrm{p}_{\mathrm{b}}(\mathrm{s})=\mathrm{p}_{\mathrm{b}}(\mathrm{s}-1)+\mu_{\mathrm{b}}+\mathrm{u}_{\mathrm{b}}(\mathrm{s})
$$

where $\mathrm{u}_{\mathrm{e}} \sim \operatorname{iid~} \mathrm{N}\left(0, \sigma_{\mathrm{e}}^{2}\right)$ and $\mathrm{u}_{\mathrm{b}} \sim \operatorname{iid} \mathrm{N}\left(0, \sigma_{\mathrm{b}}^{2}\right)$. The covariance between the stock and bond returns is $\sigma_{\mathrm{eb}}$. 
With a continuously compounded 60:40 equity-debt portfolio, the log level of the overall portfolio would satisfy the following random walk if there were no additions or payments: ${ }^{21}$

$$
\mathrm{p}(\mathrm{s})=\mathrm{p}(\mathrm{s}-1)+\mu+\mathrm{u}(\mathrm{s})
$$

with $\mathrm{u} \sim$ iid $\mathrm{N}\left(0, \sigma^{2}\right)$. To derive the values of $\mu$ and $\sigma^{2}$ we use the lognormal property of the returns.

More specifically, if $\mu_{\mathrm{i}}{ }^{*}$ is the mean return on asset $\mathrm{i}$ in level form, the mean return on the 60:40 portfolio is the weighted average $\mu *=0.6 \mu_{\mathrm{e}} *+0.4 \mu_{\mathrm{b}} *$. Because we assume the $\log$ returns to be normally distributed, $\mu *_{i}=\mu_{i}+0.5 \sigma_{i}^{2}$. This implies that

$$
\mu+0.5 \sigma^{2}=0.6\left(\mu_{\mathrm{e}}+0.5 \sigma_{\mathrm{e}}^{2}\right)+0.4\left(\mu_{\mathrm{b}}+0.5 \sigma_{\mathrm{b}}^{2}\right)
$$

where

$$
\sigma^{2}=0.36 \sigma_{\mathrm{e}}^{2}+0.16 \sigma_{\mathrm{b}}^{2}+0.48 \sigma_{\mathrm{eb}}
$$

From these two equations and the mean and variance of the log returns on stocks and bonds we can derive the log return on the portfolio and the variance of that return.

The CRSP data for the postwar period from 1946 through 1995 imply that for stocks and bonds the mean real log rates of return were 7.1 percent and 3.3 percent. ${ }^{22}$ The corresponding standard deviations were 16.6 percent for stocks and 10.4 percent for bonds. The covariance of the stock and bond returns was $\sigma_{\mathrm{eb}}=0.0081$. Taken together, these parameters imply a log

\footnotetext{
${ }^{21}$ The value of the PRA portfolio during the preretirement years is also increased by the individual's annual PRA savings.

${ }^{22}$ The bond rate of return is based on the Salomon Brothers AAA bond returns adjusted to a more typical corporate bond yield by adding two percentage points. 
average rate of return on the 60:40 portfolio of 5.9 percent with a standard deviation of 12.5 percent. ${ }^{23}$ We reduce the mean log return from 5.9 percent to 5.5 percent to reflect potential administrative costs. ${ }^{24}$

In the analysis that follows, we recognize that the adjusted mean real log return of 5.5 percent for the portfolio during the period from 1946 through 1995 is only an estimate of the relevant mean for future years. Our stochastic simulation therefore uses a two step procedure to simulate the uncertain future annual returns. For each of 10,000 simulations, we begin by generating a mean real log return on the portfolio from a normal distribution with a mean of 0.055 and a standard deviation of 0.0175 which is equal to the standard error of the estimated mean based on the number of years in the sample. We then use this estimated realization of the mean and the standard deviation of 0.125 to generate a 71 year sequence of portfolio returns from the year 2000 to 2070 . We repeat this 10,000 times.

Although equation 3.4 for $\mathrm{p}(\mathrm{s})$ describes the way that the log value of the PRA account would evolve during the accumulation years if there were no external additions, in practice the actual individual PRA account is also augmented by the fraction $\alpha$ of the individual's wage and by the distributed share of the PRA balances of those members of the cohort who die during the year. We simulate this evolution at the level of the birth cohort (rather than of the individual) by:

$$
M(s)=[1+R(s-1)] M(s-1)+\alpha w(s) N(s)
$$

\footnotetext{
${ }^{23}$ The portfolio return changes very little if we use a longer time period from 1926 to 1995.

${ }^{24}$ This estimate of the administrative cost may be compared with the cost of about 0.2 percent charged now in indexed equity funds by mutual fund companies like Vanguard and Fidelity. Bond funds generally have lower administrative charges.
} 
where $\mathrm{M}(\mathrm{s})$ is the aggregate PRA balance for the cohort as a whole, $\mathrm{R}(\mathrm{s})$ is the rate of return in period s, N(s) is the number of living members of the cohort, w(s) is the average wage and $\alpha$ is the share of wages that are saved and contributed to the PRA accounts. Since this equation is in level rather than $\log$ form, the value of $1+R(s)=\exp [r(s)]$ where $r(s)$ is the log rate of return in period s implied by

$$
r(s)=p(s)-p(s-1)=\mu+u(s)
$$

With the standard deviation of 0.125 and the assumption that the log returns are normally distributed, the "level" or "money" rate of return is 6.9 percent before subtracting the administrative costs; i.e., $\mathrm{E}[1+\mathrm{R}(\mathrm{s})]=\mathrm{E}\left[\exp (\mathrm{r}(\mathrm{s})]=\exp \left[\mathrm{E}(\mathrm{r}(\mathrm{s}))+0.5 \sigma^{2}\right]=1.069\right.$.

\subsection{The Uncertain Return on Incremental Capital}

The value of the individual's PRA annuities depends on the value of the PRA account and therefore on the market return on stocks and bonds. In contrast, the government's incremental corporate tax revenue depends on the size of the incremental capital stock and the profitability of that capital. In our nonstochastic analysis in section 2 we simplified by assuming that the size of the capital stock could be represented by the market value of the PRA account and that the corporate tax revenue could be represented by 2 percent of the PRA assets.

We now consider a more realistic evolution of the size of the capital stock and of the profitability of the capital. Let $\mathrm{K}(\mathrm{s})$ be the value of the increment to the capital stock in period s as a result of the PRA saving system begun at $s=0$. The evolution of the incremental capital stock can be written:

$$
\mathrm{K}(\mathrm{s})=\{1+[1-\tau][\mathbf{R}(\mathrm{s})-\mathrm{r} \beta-\mathrm{sltax}]+\mathrm{r} \beta\} \mathrm{K}(\mathrm{s}-1)+\alpha(\mathrm{s}) \mathrm{W}(\mathrm{s})-\mathrm{ANN}(\mathrm{s})
$$


where $\mathbf{R}(\mathrm{s})$ is the real pretax return on capital in year $\mathrm{s}, \mathrm{r}$ is the real interest rate paid by firms, $\beta$ is the ratio of debt to capital, sltax is the state and local tax paid per dollar of capital, $\tau$ is the effective marginal federal corporate tax rate on profits net of interest and of state and local tax payments, $\alpha(\mathrm{s})$ is the PRA saving deposit as a fraction of covered earnings [W (s)] and ANN (s) is the annuity withdrawals in that year.

In this notation $\mathbf{R}(\mathrm{s}) \mathrm{K}(\mathrm{s}-1)$ is the pretax incremental profits before interest expenses, i.e., the product of the marginal product of capital and the size of the incremental capital stock. Since $\beta$ is the ratio of debt to capital, $\beta \mathrm{K}(\mathrm{s}-1)$ is the corporate debt and $\mathrm{r} \beta \mathrm{K}(\mathrm{s}-1)$ is the real interest paid on that debt. ${ }^{25}$ Since most of the state and local taxes are property taxes, we approximate the total state and local tax as a fraction of the property, sltax K(s-1). Since the corporate tax at rate $\tau$ is levied on profits net of interest, the profits after taxes and interest are

$[1-\tau][\mathbf{R}(\mathrm{s})-\mathrm{r} \beta-\operatorname{sltax}] \mathrm{K}(\mathrm{s}-1)$. The division of these net profits between dividends and retained earnings is not relevant in the current context because, since both accrue to the Personal Retirement Accounts, there is no difference in their tax treatment or in their contribution to PRA assets and the associated capital stock. The other sources of change in the value of the capital stock are the addition of the PRA saving deposits, $\alpha(\mathrm{s}) \mathrm{W}(\mathrm{s})$, and the subtraction of the annuity payments, ANN(s).

Since $\mathbf{R}(\mathrm{s})$ is not a financial rate of return but the actual year to year profitability at the

${ }^{25}$ We simplify by ignoring inflation and therefore the difference between the real interest rate and the tax-deductible nominal interest rate. We take this into account, however, in the numerical value used for the corporate tax rate. 
company level ${ }^{26}$, the $\mathbf{R}(\mathrm{s})$ time series will not have the serial independence property of a financial return in an efficient market. Instead, $\mathbf{R}(\mathrm{s})$ will exhibit the serially correlated property of a business cycle variable. We have used the annual values of $\mathbf{R}(\mathrm{s})$ recently developed by Poterba (1997) to estimate the parameters of an ARIMA process. After experimenting with a variety of specifications we estimated the following specification:

(3.10) $\ln \mathbf{R}(\mathrm{s})=0.017+0.793 \mathbf{R}(\mathrm{s}-1)+0.562 \mathrm{e}(\mathrm{s}-1)+\mathrm{e}(\mathrm{s})$

where the stochastic innovation e(s) has mean zero and standard deviation 0.006 .

Although market efficiency implies that the innovations in the portfolio return process are serially independent, they can be contemporaneously correlated with the innovations in the profitability process. To simulate the simultaneous evolution of the PRA accounts and the corporate profits, we estimate the correlation between the residual in the corporate profitability equation (i.e., $\mathrm{e}(\mathrm{s})$ in equation 3.10) and the innovation in the log rate of return that drives the PRA fluctuations (i.e., $\mathrm{u}(\mathrm{s})$ in equation 3.8). Since the estimated correlation is very small, just 0.024, we do not incorporate it in our simulations.

With the process specified in equation 3.10 for generating values of $\mathbf{R}(\mathrm{s})$ it is possible to calculate the additional federal corporate profits tax associated with the incremental capital. We begin by generating 10,000 samples of the time vector of $\mathbf{R}(\mathrm{s})$ values for the year's 2000 to 2070 ,

\footnotetext{
${ }^{26}$ Pretax capital income of the nonfinancial corporate sector is the sum of pretax profits, net interest payments, and the property and profits taxes paid to state and local governments. The capital is the sum of reproducible equipment and structures at reproduction cost plus the estimated market value of the land. For more detail on the nature of these estimates, see Poterba (1997) and Feldstein, Dicks-Mireaux and Poterba(1983).
} 
and for each time vector of $\mathbf{R}(\mathrm{s})$ values, using equation 3.9 to calculate a corresponding $\mathrm{K}(\mathrm{s})$ series. For this calculation we use Poterba's estimate that the state and local taxes as a fraction of the capital stock is sltax $=0.012$. We take the corporate debt capital ratio to be $\beta=0.4$, the same share of capital that we assume in our PRA portfolio and the average share of debt on corporate balance sheets. With a real rate of interest of $r=0.033$, we have $r \beta=0.0132$. Finally, Poterba's estimate that federal taxes were 2.2 percent of capital during this period implies that $\tau[\mathrm{R}(\mathrm{s})-\mathrm{r} \beta$ - sltax $]=.022$ or, with $\mathrm{R}=.085, \mathrm{r} \beta=0.0132$ and sltax $=0.012$, that the effective rate of federal tax on this measure of taxable income was $\tau=0.37$. We then calculate the corporate tax using the same $\mathbf{R}(\mathrm{s})$ values in

$$
\operatorname{TAX}(\mathrm{s})=\mathrm{t}[\mathbf{R}(\mathrm{s})-\mathrm{r} \beta-\mathrm{sltax}] \mathrm{K}(\mathrm{s}-1) .
$$

With $\tau=0.37$, this tax equation implies federal tax revenue at the mean value of $\mathbf{R}(\mathrm{s})=0.085$ is 2.2 percent of $K(s-1)$ and therefore approximately 2.1 percent of $K(s)$.

\section{Individual Risk in the Transition from PAYGO Pensions to Investment-based Pensions}

We are now ready to examine the probability distribution of retirement incomes during the transition from the existing system to a completely investment-based system. Our emphasis is on assessing the risk that the incomes provided in this way will be judged to be too low and seeing the sensitivity of this risk to different PRA saving rules. The current results thus extend the analysis of individual risk in Feldstein and Ranguelova (1999, section 3). The earlier study looked just at the risks in a fully privatized system in the year 2070 when all retirees were assumed to have contributed to PRAs throughout their working life and to have only PRA annuities and no tax- 
financed PAYGO benefits. In the current study, we look at individuals of different birth cohorts in different years along the transition path $(2010,2020,2030,2050$ and 2070) and, for each cohort in each year, present the probability distribution of the combined income from the PAYGO benefit and the PRA annuity.

The PAYGO benefit in each year is reduced relative to the benchmark benefits according to the schedules implied in Section 2 above. For example, if we use the basic portfolio rate of return (with a mean real log return of 5.5 percent after administrative expenses), we reduce the PAYGO benefit of each age cohort in each year (relative to the benchmark benefit that would be paid if there were no PRA annuity) by the amount that such individuals would expect to receive from their PRA annuities if those annuities earned the expected rate of return ${ }^{27}$. The individual bears all of the risk - both positive and negative - associated with the uncertainty of the PRA annuity. If the PRA annuity for a particular cohort in a particular year turns out to equal the annuity that would result at the expected rate of return, the combination of the PAYGO benefit and the PRA annuity would exactly equal the benchmark benefit. Table 6 shows the PAYGO benefits for the different age cohorts in the selected years that we examine. In the early years, the PAYGO benefits remain a substantial fraction of the benchmark level. But by 2030 this ratio has begun to decline significantly and by 2070 all living cohorts are no longer receiving PAYGO benefits.

Table 6

$\underline{\text { PAYGO Benefits by Birth Cohort at Selected Dates }}$

(All figures are expressed as percentages of benchmark benefits.)

\footnotetext{
${ }^{27}$ Recall that the nonstochastic rate of return that we use is about one percent lower than the expected return based on the stochastic distribution of PRA annuities. This causes us to provide higher PAYGO annuities.
} 


$\begin{array}{ccccccc}\underline{\text { Age in Year 2000 }} & \underline{\underline{2010}} & \underline{2020} & \underline{2030} & \underline{2050} & \underline{2070} \\ 60 & 0.98 & 0.98 & 0.98 & 0.00 & 0.00 \\ 50 & 0.00 & 0.87 & 0.87 & 0.87 & 0.00 \\ 40 & 0.00 & 0.00 & 0.65 & 0.65 & 0.00 \\ 30 & 0.00 & 0.00 & 0.00 & 0.29 & 0.29 \\ 21 & 0.00 & 0.00 & 0.00 & 0.00 & 0.00\end{array}$

The risk that the combination of the PAYGO benefit and the PRA annuity will be unacceptably small relative to the benchmark benefit increases as we move to more distant future years. That risk can be reduced by increasing the PRA saving rate above the level that was adequate when uncertainty was ignored. A fundamentally different alternative approach is to provide a supplementary conditional PAYGO benefit; we examine this intergenerational risk sharing approach in section 5 .

Table 7 shows the distribution of "combined benefits" (i.e., the sum of the PAYGO and PRA benefits) corresponding to the basic PRA saving rates that we used in the nonstochastic case reported in Table 1 above: all employees save 3 percent of taxable earnings per year from the year 2000 (when the transition begins) to 2006 and then 4.25 percent of taxable earnings in each year after that. We present results for five different birth cohorts (identified by their age in year 2000) and five different future years. We report these combined benefits as fractions of the "benchmark" benefit for that cohort in that year, i.e., the level of benefit called for in current law. We present six points on the probability distribution corresponding to the $1^{\text {st }}, 2^{\text {nd }}, 5^{\text {th }}, 10^{\text {th }}, 50^{\text {th }}$ and $90^{\text {th }}$ percentiles.

Those who are 60 when the program begins have very little risk of departing from the benchmark benefits since there are few years of PRA saving before retirement and PAYGO 
benefits are therefore high relative to the benchmark. The median benefit is the benchmark level and there is less than a one percent chance of having less than 99 percent of the benchmark level of benefits at age 70 and 98 percent of the benchmark benefit at ages 80 and 90 . The columns for 2050 and 2070 show zeroes because we assume that no individuals live beyond age 100 .

The situation is similar for those who are 50 in the year 2000. They are not yet retired in the year 2010 (which is why zeroes appear in that year). When they are 70 years old (in 2020) the distribution of combined benefits is quite tight, with only a ten percent chance that the combined benefits are less than 95 percent of the benchmark. There is only a one percent chance that the benefits are less than 92 of the benchmark level. Although the distribution becomes wider as they age (because the variable annuity means more years of investment), even in the year 2050 (the last year for this cohort) only five percent of combined benefits are less than 88 percent of the benchmark.

Table 7

Combined Benefit Distributions by Birth Cohort at Selected Dates (All figures are expressed as percentages of benchmark benefits.)

$2010 \quad 2020 \quad 2030 \quad 2050 \quad 2070$

$\underline{\text { Age in Year } 2000}$ Percentile

60

$\begin{array}{rccccc}1 & 0.99 & 0.98 & 0.98 & 0.00 & 0.00 \\ 2 & 0.99 & 0.98 & 0.98 & 0.00 & 0.00 \\ 5 & 0.99 & 0.99 & 0.98 & 0.00 & 0.00 \\ 10 & 0.99 & 0.99 & 0.98 & 0.00 & 0.00 \\ 50 & 1.00 & 1.00 & 1.00 & 0.00 & 0.00 \\ 90 & 1.02 & 1.03 & 1.04 & 0.00 & 0.00 \\ & & & & & \\ 1 & 0.00 & 0.92 & 0.90 & 0.88 & 0.00\end{array}$

Transition.022699 


\begin{tabular}{|c|c|c|c|c|c|c|}
\hline & 2 & 0.00 & 0.93 & 0.90 & 0.88 & 0.00 \\
\hline & 5 & 0.00 & 0.94 & 0.91 & 0.89 & 0.00 \\
\hline & 10 & 0.00 & 0.95 & 0.92 & 0.90 & 0.00 \\
\hline & 50 & 0.00 & 1.02 & 1.01 & 0.99 & 0.00 \\
\hline & 90 & 0.00 & 1.14 & 1.21 & 1.34 & 0.00 \\
\hline 40 & 1 & 0.00 & 0.00 & 0.76 & 0.68 & 0.00 \\
\hline & 2 & 0.00 & 0.00 & 0.77 & 0.69 & 0.00 \\
\hline & 5 & 0.00 & 0.00 & 0.80 & 0.71 & 0.00 \\
\hline & 10 & 0.00 & 0.00 & 0.84 & 0.74 & 0.00 \\
\hline & 50 & 0.00 & 0.00 & 1.06 & 1.00 & 0.00 \\
\hline & 90 & 0.00 & 0.00 & 1.56 & 1.97 & 0.00 \\
\hline 30 & 1 & 0.00 & 0.00 & 0.00 & 0.39 & 0.33 \\
\hline & 2 & 0.00 & 0.00 & 0.00 & 0.41 & 0.34 \\
\hline & 5 & 0.00 & 0.00 & 0.00 & 0.46 & 0.37 \\
\hline & 10 & 0.00 & 0.00 & 0.00 & 0.53 & 0.42 \\
\hline & 50 & 0.00 & 0.00 & 0.00 & 1.07 & 0.96 \\
\hline & 90 & 0.00 & 0.00 & 0.00 & 2.95 & 4.05 \\
\hline 21 & 1 & 0.00 & 0.00 & 0.00 & 0.19 & 0.06 \\
\hline & 2 & 0.00 & 0.00 & 0.00 & 0.23 & 0.09 \\
\hline & 5 & 0.00 & 0.00 & 0.00 & 0.31 & 0.14 \\
\hline & 10 & 0.00 & 0.00 & 0.00 & 0.42 & 0.21 \\
\hline & 50 & 0.00 & 0.00 & 0.00 & 1.22 & 1.05 \\
\hline & 90 & 0.00 & 0.00 & 0.00 & 3.88 & 5.57 \\
\hline
\end{tabular}

Combined Benefits are the sum of the PAYGO benefits shown in Table 4 and the PRA annuities that result from saving 3 percent of taxable earnings from 2000 to 2006 and 4.25 percent in all future years. The PRA accounts earn a stochastic return with an expected real mean log return of 5.5 percent and a standard deviation of 12.5 percent.

But when we get to the cohort that is forty years old in 2000 there is a greater risk of what might be considered unacceptably low benefits. Those who are 40 years old in 2000 reach retirement age in 2027 and are 70 years old in 2030. Our analysis shows that although the median combined benefit for this group is 106 percent of the benchmark, there is a 10 percent chance that the combined benefit will be less than 84 percent of the benchmark and a five percent chance that it 
will be 77 percent of the benchmark. These 5 and 10 percent benchmark ratios are 10 percentage points lower when the cohort reaches age 100.

The youngest cohort in our analysis are 21 years old in the year 2000 and therefore never receive any PAYGO benefits. With a 3 percent saving rate for a brief period followed by a 4.25 percent saving rate, there is a considerable chance that their PRA benefits at retirement will be unacceptably low. Table 7 shows that although the median benefit for this group at age 71 (in 2050) is 122 percent of the benchmark, there is a 10 percent change that it will be less than 42 percent of the benchmark and a 5 percent chance that it will be less than 31 percent of the benchmark level.

These risks can be reduced substantially by increasing the PRA saving deposits for younger cohorts. Before looking at the specific results, it should be stressed that this could be achieved either by requiring younger cohorts to make larger saving deposits into their PRA accounts or by having the government make those deposits from general revenue. This issue of the distribution of the burden during the transition is separate from the efficiency of these deposits in reducing risk and will not be considered further here.

Because the risks of low combined benefits are greatest for the employees who are aged 30 and younger at the start of the transition in the year 2000, we present results only for these younger cohorts. Table 8 compares three different PRA saving rules. For all employees born before 1960 , i.e, who were 40 or older in 2000 , each of the rules has a 3 percent saving rate from 2000 to 2006 followed by a 4.25 percent rate, i.e., the same rule displayed in Table 7. Rule 8A has a higher rate for those born after 1959: a 5 percent saving rate from 2000 to 2006 followed by a 6.25 percent rate. Rule $8 \mathrm{~B}$ raises these rates to 5.00 percent followed by 6.25 percent for 
individuals between 31 and 40 in 2000 and to 6.0 percent and 7.25 percent for those who were less than 31 in 2000 . Finally Rule $8 \mathrm{C}$ raises the rate to 8.25 for those who were less than 31 in 2000 . Each successive rule reduces the risk of a relatively low level of combined benefits but does so at an increasing cost in terms of the required PRA saving rate.

With Rule 8C, the group that is 30 years old in 2000 has only a 10 percent chance of receiving combined benefits of less than 82 percent of the benchmark level when they are 80 years old and only a five percent chance that those benefits would be less than 68 percent of the benchmark level. As they reach 100 years old, these values decline to 57 percent and 47 percent, lower than most individuals would want tolerate.

But since the median payment for this birth cohort is more than twice the benchmark benefit at age 80 and 1.82 times the benchmark at 100, it may be possible for private markets to provide a way for individuals to trade some of the upside potential (in the top half of the probability distribution) for greater protection when there are bad market outcomes. We do not explore this further here but turn in the next section to ways in which taxpayers might provide a guarantee. 
Table 8

Effects of Alternative Saving Rules on

Combined Benefit Distributions by Birth Cohort at Selected Dates

(All figures are expressed as percentages of benchmark benefits.)

\begin{tabular}{|c|c|c|c|c|c|}
\hline$\underline{\text { Rule \& Saving Rates* }}$ & $\underline{\text { Age in Year } 2000}$ & $\underline{\text { Percentile }}$ & $\underline{2050}$ & $\underline{2070}$ & \\
\hline \multirow[t]{2}{*}{ Rule 8a } & & 30 & 1 & 0.43 & 0.34 \\
\hline & & & 2 & 0.47 & 0.36 \\
\hline \multirow[t]{8}{*}{$5 \%, 6.25 \%$} & & & 5 & 0.55 & 0.41 \\
\hline & & & 10 & 0.64 & 0.48 \\
\hline & & & 50 & 1.47 & 1.30 \\
\hline & & 21 & 1 & 0.28 & 0.09 \\
\hline & & & 2 & 0.35 & 0.13 \\
\hline & & & 5 & 0.47 & 0.21 \\
\hline & & & 10 & 0.62 & 0.32 \\
\hline & & & 50 & 1.85 & 1.58 \\
\hline \multirow[t]{2}{*}{ Rule 8b } & & 30 & 1 & 0.46 & 0.35 \\
\hline & & & 2 & 0.50 & 0.37 \\
\hline \multirow[t]{8}{*}{$6 \%, 7.25 \%$} & & & 5 & 0.59 & 0.43 \\
\hline & & & 10 & 0.70 & 0.51 \\
\hline & & & 50 & 1.67 & 1.48 \\
\hline & & 21 & 1 & 0.33 & 0.11 \\
\hline & & & 2 & 0.40 & 0.15 \\
\hline & & & 5 & 0.55 & 0.25 \\
\hline & & & 10 & 0.72 & 0.37 \\
\hline & & & 50 & 2.16 & 1.85 \\
\hline \multirow[t]{2}{*}{ Rule 8c } & & 30 & 1 & 0.50 & 0.37 \\
\hline & & & 2 & 0.56 & 0.40 \\
\hline \multirow[t]{8}{*}{$8 \%, 9.25 \%$} & & & 5 & 0.68 & 0.47 \\
\hline & & & 10 & 0.82 & 0.57 \\
\hline & & & 50 & 2.07 & 1.82 \\
\hline & & 21 & 1 & 0.42 & 0.14 \\
\hline & & & 2 & 0.52 & 0.19 \\
\hline & & & 5 & 0.70 & 0.31 \\
\hline & & & 10 & 0.93 & 0.48 \\
\hline & & & 50 & 2.78 & 2.39 \\
\hline
\end{tabular}

Transition.022699 
Combined Benefits are the sum of the relative PAYGO benefits shown in Table 6 and the PRA annuities that result from saving 3 percent of taxable earnings from 2000 to 2006 and 4.25 percent in all future years. The PRA accounts earn a stochastic return with an expected real mean log return of 5.5 percent and a standard deviation of 12.5 percent.

*The saving rule is described by two numbers for each age group. The first number is the saving rate from 2000 to 2006. The second is the saving rate after that.

The need for some supplementation is even clearer when we look at those who are 21 years old in 2000 . While the median benefits for this group at age 70 would be 2.78 times the benchmark benefit, there is a five percent chance that the benefits are less than 70 percent of the benchmark and a one percent chance that the benefits are less than 42 percent of the benchmark. The probability distribution implies more risk at older ages. Once again this suggests the potential gain from private trades of upside potential for downside protection or from a government provided protection of benefits.

A key point to be emphasized is that even the most conservative option, Rule $8 \mathrm{C}$, requires a tax of only 9.25 percent for the most heavily taxed younger cohorts, less than half of what they would pay after 2030 to maintain the level of benefits. Individuals may respond to this risk by saving more voluntarily or seeking market ways to reduce the risk through stock market options.. The extent to which they do so will depend on different attitudes about risk and about the tradeoff between saving more during working years in order to reduce the risk of low income during retirement.

\section{Government Guarantees and Intergenerational Transfers}


The analysis of section 4 shows that although an increased saving rate can reduce the risk of relatively low combined benefits, it does so only at a cost of decreased consumption during working years and does not completely eliminate the risk. We therefore explore an alternative approach in which the government guarantees the benefits by providing a conditional benefit equal to the difference between the benchmark benefit and the combined benefit that the individual receives from the PAYGO and PRA annuities. ${ }^{28}$

We recognize that this guarantee could encourage excessive risk-taking by individuals to the extent that they are free to select more risky portfolios. One possible way to eliminate this incentive is to define the guarantee in terms of the "standard portfolio." In such an approach, the government would provide a conditional benefit equal to the difference between the benchmark benefit and the combined benefit that the individual would have received from a combination of PAYGO and PRA annuities if the PRA funds had been invested in the "standard portfolio" consisting of the 60 percent broad based equity fund and the 40 percent bond fund. In this way an individual is completely protected if he or she invests in the "standard portfolio" but bears the full benefit or cost of the risks associated with alternative portfolios. Since we focus our analysis in this paper on the risks associated with the "standard portfolio," we shall not discuss the issue of alternative portfolios further.

The cost of these pension guarantees depends on the rate at which individuals make PRA saving deposits during their preretirement years, with higher saving rates requiring smaller

${ }^{28}$ This is the approach analyzed in Feldstein and Ranguelova (1999) for a single year rather than for the entire transition path. The tables in this section correspond to the single Table 3 in that paper. 
conditional guarantee payments. We therefore focus on the most expensive of the cases that we have considered, the base case in which all working individuals save 3 percent of their taxable earnings from the year 2000 to 2006 and then save 4.25 percent of their taxable earnings, the amounts that we analyzed in the nonstochastic case and that determine the future path of PAYGO benefits.

Table 9 shows the distribution of the aggregate benefit shortfall for the total of all cohorts of retirees in each year, i.e., of the amount that would be necessary to supplement the combined benefits of all cohorts in each year to bring each cohort's total benefit up to the benchmark level. Each entry in the table shows the probability that the total burden required to finance the conditional benefits is below the specified amount; e.g., there is a 95 percent probability that the conditional benefits in the year 2030 would be less than 2.36 percent of earnings.

In 2010 and 2020 there is a 99 percent probability that the conditional transfer would be less than one percent of earnings. Even in 2070, when the transition to the investment-based system is virtually complete (except for retirees who are over age 90), there is a 50 percent probability that virtually no transfer (i.e., less than one-tenth of one percent of covered earnings) would be needed. In the worst 10 percent of cases, the conditional transfer exceeds 11.6 percent of earnings and in the worst one percent of the cases the conditional transfer exceeds 15.5 percent of earnings. In considering these risks to taxpayers, it should be recalled that the payroll tax of 18.7 percent that would have been required in a pure PAYGO system has been completely eliminated and replaced with the PRA saving deposits of 4.25 percent of taxable earnings. Thus there is only about one chance in 50 that the combination of the PRA saving deposits and the tax required for the conditional benefit will exceed the 18.7 percent PAYGO tax that would be required in the pure 
PAYGO system. There is a 98 percent probability that the combined cost to the taxpayers of the PRA system with the conditional guarantee benefit would be less costly. Moreover, in the nearly 50 percent of simulations in which no guarantee payment is needed, the retirees receive more income from the PRA than they would have from the benchmark PAYGO benefit.

Table 9

Distribution of Conditional Guarantee Payments

for Benchmark as Minimum Total Benefit

(All figures are expressed as percentages of taxable earnings.)

$\begin{array}{lcccccccc}\text { Percentile } & \underline{2010} & \underline{2020} & \underline{2030} & \underline{2050} & \underline{2070} & & & \\ & & & & & & & \\ 10 & 0.00 & 0.00 & 0.00 & 0.00 & 0.00 & & & \\ 20 & 0.00 & 0.00 & 0.00 & & 0.00 & 0.00 & & \\ 30 & 0.00 & 0.00 & 0.00 & 0.00 & 0.00 & & & \\ 40 & 0.00 & 0.00 & 0.00 & 0.00 & 0.00 & & & \\ 50 & 0.00 & 0.00 & 0.01 & 0.02 & 0.07 & & & \\ 60 & 0.00 & 0.03 & & 0.17 & 1.01 & 1.48 & & \\ 70 & 0.01 & 0.15 & 0.74 & 3.32 & 4.74 & & & \\ 80 & 0.03 & 0.32 & 1.32 & 5.57 & 8.25 & & & \\ 90 & 0.05 & & 0.50 & & 1.98 & & 7.75 & 11.63 \\ 95 & 0.06 & 0.62 & 2.36 & 9.00 & 13.49 & & & \\ 98 & 0.08 & 0.74 & 2.72 & 9.98 & 14.85 & & & \\ 99 & 0.08 & 0.81 & 2.87 & 10.49 & 15.55 & & & \end{array}$


Although these conditional guarantee payments represent transfers from the working generation of taxpayers to the generation of retirees, there is a high probability that much or all of the transfer in each year can be financed by the incremental corporate income tax payments that result from the incremental saving caused by the PRA system. We calculate for each year the distribution of the difference between the conditional transfer required to bring the combined benefit up to the benchmark level and the incremental corporate tax revenue available for that purpose. If the incremental corporate tax revenue is not sufficient to finance the conditional transfer, we say that a "net transfer" is required. Table 10 shows the distribution of Net Transfers. The incremental corporate tax revenue is sufficient to finance all of the required transfers in 2010 and 2020. In 2030, the probability of any net transfer is reduced to two percent and the probability of a net transfer greater than one percent of earnings is reduced to less than one percent. Even in 2050, there is only a ten percent probability of any net transfer. The maximum risk of transfers occurs in 2070 when the phase-in of the PRA system is complete. In the worst five percent of cases in 2070, the net transfer is 5.6 percent of covered earnings. Combining this with the PRA deposits of 4.25 percent of earnings gives a total net burden on taxpayers of 9.85 percent of earnings, about half of the payroll tax that would be required in that year with a pure PAYGO system. There is only a one percent chance that the sum of the 4.25 percent PRA deposit and the net transfer 9.52 percent of earnings will exceed 13.77 percent of earnings or about two-thirds of the payroll tax rate in the pure PAYGO system. 
Table 10

Distribution of Net Transfers: Conditional Guarantee Payments

In Excess of Available Corporate Tax Revenue

(All figures are expressed as percentages of taxable earnings.)

$\begin{array}{ccccccccc}\text { Percentile } & \underline{2010} & & \underline{2020} & & \underline{2030} & \underline{2050} & \underline{2070} \\ 10 & 0.00 & 0.00 & 0.00 & 0.00 & 0.00 & & \\ 20 & 0.00 & 0.00 & 0.00 & 0.00 & 0.00 & \\ 30 & 0.00 & 0.00 & 0.00 & 0.00 & 0.00 & \\ 40 & 0.00 & 0.00 & 0.00 & 0.00 & 0.00 & \\ 50 & 0.00 & 0.00 & 0.00 & 0.00 & 0.00 & \\ 60 & 0.00 & 0.00 & & 0.00 & 0.00 & 0.00 \\ 70 & 0.00 & 0.00 & 0.00 & 0.00 & 0.00 & \\ 80 & 0.00 & 0.00 & 0.00 & 0.00 & 0.12 & \\ 90 & 0.00 & 0.00 & & 0.00 & 1.84 & 3.23 \\ 95 & 0.00 & 0.00 & 0.00 & 3.24 & 5.63 & \\ 98 & 0.00 & 0.00 & 0.47 & 4.58 & 8.09 & \\ 99 & 0.00 & 0.00 & 0.79 & 5.44 & 9.52 & \end{array}$




\section{An Expected Utility Evaluation ${ }^{29}$}

Although we believe that displaying the probability distributions of possible outcomes is the best way to indicate the risks of the alternative investment-based options, in this section we present explicit summary calculations based on expected values of constant relative risk aversion (CRRA) utility functions. We focus on the case of the individual who is 21 in the year 2000 and for whom the risk of the PRA option is greatest.

To evaluate the PRA options presented in section 4 we consider a representative individual with expected utility function $E=E\left[\Sigma p_{t} \beta^{t-21} u\left(C_{t}\right)\right]$ where the summation is from $t=21$ to $t=$ 100 and $\mathrm{u}\left(\mathrm{C}_{\mathrm{t}}\right)=\left(\mathrm{C}_{\mathrm{t}}{ }^{1-\gamma}-1\right) /(1-\gamma)$. Here $\mathrm{E}$ is the expectation operator, $\mathrm{p}_{\mathrm{t}}$ is the probability of surviving to age $t$ from age $21, \beta$ is the time discount factor at which utility is discounted, and $\gamma$ is the coefficient of relative risk aversion. We do the analysis with time discount factors of 0.98 ; alternative calculations with a greater discount factor $(\beta=0.96)$ and with no time discounting factor $(\beta=1)$ have very little effect on the results that we report below.

We recognize the restrictive nature of this specification. The function is additively separable and the relative risk aversion in each period, $-u^{\prime \prime} c / u^{\prime}=\gamma$, is a constant and is independent of age. Despite these limitations, these calculations may be useful to some readers as a supplement to the direct information of the outcome distributions.

The individual who is age 21 in 2000 earns the age specific wage for this cohort projected by the Social Security actuaries and pays a proportional income tax equal to 20 percent of that wage. We consider a variety of different PRA saving rates. With a 6 percent PRA saving rate, the

\footnotetext{
${ }^{29}$ This section draws heavily on Feldstein and Ranguelova (1998), section 5.
} 
net income during the working years from age 21 to age 66 is 74 percent of the gross wage. ${ }^{30}$ The individual is assumed to do no other saving, making the consumption in each preretirement year the same 74 percent of pretax wages. ${ }^{31}$ During retirement the individual's consumption is the variable annuity that is generated by the PRA savings since this age cohort no longer contributes to the PAYGO system.

We contrast each of the possible PRA plans with the PAYGO system in which the tax rate is 18.7 percent, making the net consumption during the preretirement years equal to 62 percent of preretirement income. This PAYGO system is assumed to provide the benchmark level of benefits prescribed in current law during each retirement year with no uncertainty.

The coefficient of relative risk aversion is the key parameter in this expected utility evaluation. We do not impose an explicit value of the relative risk aversion on the problem but calculate for each saving rate the coefficient of relative risk aversion that would make the representative individual prefer the "riskless" PAYGO program to the PRA program. We then repeat the analysis for the PRA system with the government guarantee.

We drew 10,000 independent histories of the 80 year sequence (from age 21 in 2000 to age 100 in 2079) of returns on the PRA savings of the representative individual and calculated the expected utility value associate with each value of $\gamma$. Our calculations show that the PRA

${ }^{30}$ This represents a simplification in several ways. Although we are looking at wages for the years beginning in 2000, we are ignoring the transition problem and comparing a fully phased in PRA system with the PAYGO system that would also exist in the more distant future. We do this to avoid the complexities of modeling the transition. We also simplify by treating the projected wages as the marginal product of capital from which all taxes and saving are subtracted.

${ }^{31}$ The lack of other saving reduces the individual's level of retirement consumption and therefore makes the individual's utility more sensitive to fluctuations in the return to PRA saving. 
with a 3 percent saving rate is preferable to the PAYGO system for the relative risk aversion coefficient up to $\gamma=2.6$. With a 5 percent saving rate the critical value of $\gamma$ is 3.2 while with a 9 percent saving rate the PRA system is preferred to PAYGO for all values of $\gamma$ less than 3.85.

In considering these critical values of $\gamma$ it is useful to consider the implication of different $\gamma$ values for the rate at which the marginal utility of consumption declines as income rises. A value of $\gamma=2.6$ implies that a doubling of income causes the marginal utility of another dollar of income to fall by a factor of 6.06 , i.e., by $2^{2.6}$. Each reader will have to decide for himself or herself whether this value of $\gamma$ is "high" or "low". 32 Our judgement is that a value of $\gamma$ that causes such a sharp decline in the marginal utility of income is very high. This in turn implies that individuals would prefer any of the PRA systems to the PAYGO system.

We recognize that the values of $\gamma$ inferred in the finance literature from the difference between the yields on stocks and on "risk free" treasury bills are substantially higher than these critical values of $\gamma \cdot{ }^{33}$ We regard those market based values of $\gamma$ as implausibly high and appropriately characterized as an equity premium "puzzle."

\subsection{Evaluating Government Guarantee Plans with CRRA Expected Utility}

When we turn from the pure individualistic PRA system to one with a government guarantee, we can no longer focus on a single age cohort but must consider the benefits received

${ }^{32}$ Feldstein and Ranguelova(1998), section 5, presents a mental experiment that may help each reader to decide what value of $\gamma$ reflects his or her own preferences.

${ }^{33}$ See for example Mehra and Prescott (1985) and Kocherlakota (1996). 
by all retirees aged 65 through 100 and the taxes paid by employees of all ages. We therefore examine the situation during a representative year after the PRA system is fully phased in. We compare the possible outcomes of the PRA system (for alternative possible saving rates) with the PAYGO system in the long-run with an 18.7 percent tax rate.

More specifically, we calculate the expected value of a social welfare function in the first year in which the PRA system is fully phased in. This is the year 2079 when the youngest workers in 2000 (those who are then 21 years old) have reached 100, the oldest age that we consider in our analysis. The value of the social welfare function in that year is the sum of the expected utilities of the employed taxpayers and the retirees: $\mathrm{SWF}=\mathrm{E}\left[\Sigma \mathrm{N}_{\mathrm{j}} \mathrm{u}\left(\mathrm{C}_{\mathrm{j}}\right)\right]$ where the summation is now over the 80 cohorts identified by age (from $\mathrm{j}=21$ to $\mathrm{j}=100$ ), $E$ is again the expectations operator, $N_{j}$ is the number of individuals in cohort $\mathrm{j}$ in the year 2079 , and $u\left(C_{j}\right)$ is the utility of the consumption of the representative individual in cohort $\mathrm{j}$ in that year. The form of the utility function is the same CRRA function specified above. In each of the 10,000 simulations that we do, we simulate the PRA accumulation of each cohort over the 80 year horizon from 2000 until 2079 and then calculate the associated PRA annuity in that year for each retiree cohort. We then specify that the individuals in each retiree cohort consume the greater of the benchmark benefit and the PRA annuity of that cohort in that year. ${ }^{34}$

${ }^{34}$ This expected social welfare function value for a single year is of course different from the expected lifetime utility that we used to evaluate the choice between PRA and PAYGO plans. It would be desirable to use a framework in which for each of the 80 cohorts we evaluated the expected present value of lifetime utility. Unfortunately, the data requirements for that calculation stretch further into the future than the projections of the Social Security actuaries and the Census bureau. 
Retirees thus face no risk of consuming less than the benchmark benefit. All of the adverse uncertainty is focused on the taxpayers who must pay an uncertain tax bill. In particular, with a 6 percent PRA saving rate and a 20 percent income tax, the consumption of workers in cohort $\mathrm{j}$ is 74 percent of the cohort specific wage unless they are called upon to pay a supplementary tax to fill the gap between a low PRA annuity and the benchmark benefit. As we noted above, the first source of revenue to fill this gap would be the incremental corporate tax revenue that results from the PRA capital. In our analysis we assume that employees make annual adjustments to their consumption when needed to fill the retiree income gap even though some form of smoothing behavior would reduce the adverse utility effects of these uncertain extra tax burdens.

We contrast this PRA system with a riskless PAYGO system with an 18.7 percent tax and with the benchmark benefits during retirement. We find that the PRA system with the government guarantee dominates the PAYGO system for each of the saving rates between 3 percent and 9 percent and for every CRRA parameter value up to $\gamma=40$ ! These simulations tell us that a CRRA individual with any degree of risk aversion that we have considered would prefer the PRA system with government guarantees to the current PAYGO system. ${ }^{35}$

\section{Risk Aspects of a Mixed System of PAYGO and Investment-Based Benefits}

We return now to the type of mixed system that combines PAYGO and investment-based benefits that we discussed in the nonstochastic analysis of section 2.4. We fix the PAYGO tax rate

\footnotetext{
${ }^{35}$ The magnitude of the gain from shifting from a PAYGO system to a PRA system with a government guarantee depends on the value of $\gamma$. Smetters' (1999) analysis of the cost of riskbearing in investment-based accounts relies implicitly on market based measures of the risk premium. The high value of $\gamma$ implicit in his analysis may explain his conclusion about the limited gain from adopting a PRA type plan. 
at its current 12.4 percent level for all future years. We also have a constant rate of saving in the PRA accounts equal to 2.3 percent of covered earnings.

The nonstochastic simulation in section 2.4 showed that this combination of PAYGO benefits and PRA annuities would provide more than the PAYGO level of benefits if the real return in the PRA accounts is 5.5 percent. We now recognize the uncertainty of the PRA returns. We begin with the assumption that the retirees bear all of the risk of this uncertain return. Thus, they receive either more or less than the benchmark benefits. We then consider an alternative arrangement in which retirees are guaranteed to receive at least the benchmark level of benefits.

Table 11 shows the probability distributions of the combination of PAYGO benefits ${ }^{36}$ and PRA annuities for different birth cohorts at selected years during the transition. These combined benefits are expressed as multiples of the benchmark benefits.

For those who are 60 years old in the year 2000, the time to accumulate PRA funds is too short for the uncertainty to matter. The 50 year-olds have fifteen years of accumulation and the uncertain returns during the annuity period. The median level of the combined payout for this cohort remains very close to the benchmark benefit, declining from 103 percent of the benchmark at age 70 to 101 percent at age 100 . In the worst one percent of simulations for this group, the combined benefit remains above 94 percent of the benchmark benefit. As compensation for this downside risk, there is a 10 percent probability that the benefits will exceed 112 percent of the benchmark level at age 70 and higher multiples in subsequent years.

${ }^{36}$ In this stochastic context, the PAYGO benefit for each individual in each year is calculated as the benchmark benefit minus the 75 percent of the PRA annuity that would be paid if the individual's PRA savings had earned the 5.5 percent real return. 
The 40 year olds in 2000 are also exposed to little downside risk in this mixed system. Even in the worst one percent of cases, the level of combined benefits exceeds 90 percent of the benchmark at age 70 and 86 percent at age 90 . The upside potential is now greater, with a ten percent chance of a combined benefit that exceeds the benchmark by 42 percent at age 70 and by 68 percent at age 90 .

The highest risk cases are of course the youngest cohorts since they will have the greatest exposure to PRA benefits relative to PAYGO benefits when they retire. The 21 year olds in 2000 will have made PRA contributions of 2.3 percent throughout their working life and will therefore have the full risk not only in the transition but thereafter. The median combined benefit for this group is 127 percent of the benchmark PAYGO benefit. There is one chance in ten that they will face benefits of less than 79 percent of the benchmark at age 71 and 67 percent at age 91 . There is only one chance in 100 of receiving less than 66 percent of the benchmark benefits at age 71 and 59 percent at age 91 . Another way of describing the limit to the risk faced by this cohort is to note that for this cohort the PAYGO benefits would represent 55 percent of the benchmark level of benefits so any value in the PRA accounts would be in excess of that. An indication of the compensating upside potential is that there is a 10 percent chance that the combined benefits will be nearly three times the benchmark benefit at age 71 and an even higher multiple in later years.

Table 11

Combined Benefit Distributions by Birth Cohort at Selected Dates Mixed PAYGO and Investment-Based System 
(All figures are expressed as percentages of benchmark benefits.)

\begin{tabular}{|c|c|c|c|c|c|c|}
\hline Age in Year 2000 & $\underline{\text { Percentile }}$ & $\underline{2010}$ & $\underline{2020}$ & $\underline{2030}$ & $\underline{2050}$ & $\underline{2070}$ \\
\hline \multirow[t]{6}{*}{60} & 1 & 1.00 & 0.99 & 0.99 & 0.00 & 0.00 \\
\hline & 2 & 1.00 & 0.99 & 0.99 & 0.00 & 0.00 \\
\hline & 5 & 1.00 & 0.99 & 0.99 & 0.00 & 0.00 \\
\hline & 10 & 1.00 & 0.99 & 0.99 & 0.00 & 0.00 \\
\hline & 50 & 1.01 & 1.00 & 1.00 & 0.00 & 0.00 \\
\hline & 90 & 1.02 & 1.03 & 1.03 & 0.00 & 0.00 \\
\hline \multirow[t]{6}{*}{50} & 1 & 0.00 & 0.97 & 0.95 & 0.94 & 0.00 \\
\hline & 2 & 0.00 & 0.97 & 0.96 & 0.94 & 0.00 \\
\hline & 5 & 0.00 & 0.98 & 0.96 & 0.95 & 0.00 \\
\hline & 10 & 0.00 & 0.99 & 0.97 & 0.95 & 0.00 \\
\hline & 50 & 0.00 & 1.03 & 1.02 & 1.01 & 0.00 \\
\hline & 90 & 0.00 & 1.12 & 1.16 & 1.25 & 0.00 \\
\hline \multirow[t]{6}{*}{40} & 1 & 0.00 & 0.00 & 0.90 & 0.86 & 0.00 \\
\hline & 2 & 0.00 & 0.00 & 0.91 & 0.86 & 0.00 \\
\hline & 5 & 0.00 & 0.00 & 0.93 & 0.88 & 0.00 \\
\hline & 10 & 0.00 & 0.00 & 0.95 & 0.89 & 0.00 \\
\hline & 50 & 0.00 & 0.00 & 1.09 & 1.05 & 0.00 \\
\hline & 90 & 0.00 & 0.00 & 1.42 & 1.68 & 0.00 \\
\hline \multirow[t]{6}{*}{30} & 1 & 0.0 & 0.00 & 0.00 & 0.74 & 0.70 \\
\hline & 2 & 0.00 & 0.00 & 0.00 & 0.75 & 0.71 \\
\hline & 5 & 0.00 & 0.00 & 0.00 & 0.78 & 0.73 \\
\hline & 10 & 0.00 & 0.00 & 0.00 & 0.82 & 0.75 \\
\hline & 50 & 0.00 & 0.00 & 0.00 & 1.15 & 1.08 \\
\hline & 90 & 0.00 & 0.00 & 0.00 & 2.33 & 3.00 \\
\hline \multirow[t]{6}{*}{21} & 1 & 0.00 & 0.00 & 0.00 & 0.66 & 0.59 \\
\hline & 2 & 0.00 & 0.00 & 0.00 & 0.68 & 0.60 \\
\hline & 5 & 0.00 & 0.00 & 0.00 & 0.73 & 0.63 \\
\hline & 10 & 0.00 & 0.00 & 0.00 & 0.79 & 0.67 \\
\hline & 50 & 0.00 & 0.00 & 0.00 & 1.27 & 1.17 \\
\hline & 90 & 0.00 & 0.00 & 0.00 & 2.89 & 3.88 \\
\hline
\end{tabular}

Combined Benefits are the sum of the PAYGO benefits generated by the 12.4 percent payroll tax and the PRA annuities that result from saving 2.3 percent of taxable earnings in all years. The PRA accounts earn a stochastic return with an expected real mean log return of 5.5 percent and a standard deviation of 12.5 percent.

Transition.022699 
As we noted earlier, individuals will differ in their attitudes toward risk and toward the timing of consumption. Some individuals would save more than the required 2.3 percent in order to reduce the risk of a inadequate income in retirement. Others may seek market-based opportunities to reduce the downside risk by trading some of the upside potential.

It is again possible for the government to reduce the risk to retirees by an intergenerational guarantee, a conditional benefit that guarantees that the combination of the PRA benefit and the PAYGO benefit is at least as large as the benchmark benefit. The guarantee that we assume takes the following form: Each retiree is guaranteed that the sum of his or her payment from the government (including the basic PAYGO benefit plus any conditional benefit) plus 75 percent of PRA payment for the year will be at least equal to the benchmark benefit. Operationally, if the basic PAYGO benefit (based on the assumption of a 5.5 percent real return) plus 75 percent of the individual's PRA annuity is less than the benchmark benefit, the government supplements the PAYGO benefit by enough to bring that total up to the benchmark benefit. ${ }^{37}$ The individual thus receives the benchmark benefit amount plus 25 percent of the PRA annuity. ${ }^{38}$

${ }^{37}$ Recall that if the individuals are given discretion about the investment that they make with the PRA funds, the guarantee would be defined in terms of the annuity that would have been provided by investments in the "standard portfolio" of a 60 percent broad stock fund and 40 percent corporate bond fund. Thus if the if the basic PAYGO benefit (based on the assumption of a 5.5 percent real return) plus 75 percent of what the individual's PRA annuity would be if the PRA deposits had always been invested in the "standard fund" is less than the benchmark benefit, the government supplements the PAYGO benefit by enough to bring that total up to the benchmark benefit.

${ }^{38}$ In the unlikely event that the PRA annuity implied by the standard portfolio is so large that 75 percent of its value exceeds the benchmark benefit, the retiree gets the full PRA annuity and no government funds. 
The cost to the taxpayers of providing this guarantee is relatively small as shown in Table 12. In 2050 , there is essentially a 50 percent chance that no money need be given to any of the retired cohorts. By 2070, that is still essentially true; the median value of the transfer in the 10,000 simulations is equal to only .07 percent of earnings in that year. There is only one chance in 10 that the funds needed exceed 5.32 percent of covered earnings and only one chance in 100 that the required funds exceed 6.92 percent of covered earnings.

Shifting from these gross tax requirements to the revenue needed net of the incremental corporate tax reduces the needed funds substantially, as shown in Table 13. Even in 2070 there is only one chance in ten that any net transfer will be required and only one chance in fifty that the net transfer will exceed 3.7 percent of covered earnings. Combining the 12.4 percent PAYGO tax, the 2.3 percent PRA deposits and the 3.7 percent net transfer still gives a total of 18.4 percent of covered earnings, less than the payroll tax that would be required in a pure PAYGO system.

\section{Conclusion}

In this paper we examine the feasibility of a transition from the existing pay-as-you-go system of Social Security to a system that is completely or partially investment-based, using individual accounts invested in stock and bond mutual funds. Our analysis focuses on the uncertainty of portfolio returns and the volatility of capital stock profitability. 
Table 12

Distribution of Conditional Guarantee Payments for Mixed PAYGO-PRA System

(All figures are expressed as percentages of taxable earnings.)

$\begin{array}{ccccccc}\text { Percentile } & \underline{2010} & \underline{2020} & \underline{2030} & \underline{2050} & \underline{2070} & \\ 10 & & 0.00 & 0.00 & 0.00 & 0.00 & 0.00 \\ 20 & 0.00 & 0.00 & 0.00 & 0.00 & 0.00 & \\ 30 & 0.00 & 0.00 & 0.00 & 0.00 & 0.00 & \\ 40 & & 0.00 & 0.00 & 0.00 & 0.00 & 0.00 \\ 50 & & 0.00 & 0.00 & 0.00 & 0.01 & 0.07 \\ 60 & 0.00 & 0.01 & 0.09 & 0.55 & 1.02 & \\ 70 & 0.01 & 0.08 & 0.37 & 1.66 & 2.50 & \\ 80 & 0.01 & 0.17 & 0.64 & 2.66 & 3.93 & \\ 90 & 0.03 & 0.26 & 0.96 & 3.63 & 5.32 & \\ 95 & 0.03 & 0.32 & 1.14 & 4.17 & 6.08 & \\ 98 & 0.04 & 0.38 & 1.31 & 4.60 & 6.64 & \\ 99 & 0.05 & 0.41 & 1.38 & 4.82 & 6.92 & \end{array}$

Table 13

Distribution of Net Transfers: Conditional Guarantee Payments

In Excess of Available Corporate Tax Revenue in Mixed PAYGO-PRA System

(All figures are expressed as percentages of taxable earnings.)

$\begin{array}{cccccc}\text { Percentile } & \underline{2010} & \underline{2020} & \underline{2030} & \underline{2050} & \underline{2070} \\ 10 & 0.00 & 0.00 & 0.00 & 0.00 & 0.00 \\ 20 & 0.00 & 0.00 & 0.00 & 0.00 & 0.00 \\ 30 & 0.00 & 0.00 & 0.00 & 0.00 & 0.00 \\ 40 & 0.00 & 0.00 & 0.00 & 0.00 & 0.00 \\ 50 & 0.00 & 0.00 & 0.00 & 0.00 & 0.00 \\ 60 & 0.00 & 0.00 & 0.00 & 0.00 & 0.00 \\ 70 & 0.00 & 0.00 & 0.00 & 0.00 & 0.00 \\ 80 & 0.00 & 0.00 & 0.00 & 0.00 & 0.00 \\ 90 & 0.00 & 0.00 & 0.00 & 0.44 & 1.30 \\ 95 & 0.00 & 0.00 & 0.00 & 1.09 & 2.56 \\ 98 & 0.00 & 0.00 & 0.03 & 1.74 & 3.66 \\ 99 & 0.00 & 0.00 & 0.22 & 2.15 & 4.52\end{array}$


We begin by studying how a simple transition could work with no uncertainty. Using the 1998 Social Security Trustees projections and economic assumptions, we show that Personal Retirement Account deposits of three percent of taxable earnings in addition to the existing 12.4 percent payroll tax would be sufficient to start the transition and that the resulting 15.4 percent would be the maximum saving-plus-tax share of taxable earnings rate that would ever be necessary in the transition to a completely investment-based system. Over time the payroll tax could be reduced (because PRA annuities reduce the need for PAYGO benefits) while the PRA saving rate rises to 4.25. By 2050 the combined saving-plus-tax payments are less than 10 percent and by 2070 (and after) the payroll tax is eliminated and the only remaining payment is the PRA saving rate of 4.25 percent.

Our analysis then shifts to the more modest goal of a mixed system that maintains the current 12.4 percent payroll tax and uses the investment-based system to finance about one-third of benefits. We show that the Social Security benefits projected in current law (the "benchmark benefits") can be financed by supplementing the PAYGO benefits that are possible with a 12.4 percent payroll tax with PRA annuities that result from saving 2.3 percent of taxable earnings.

We then use the postwar experience to assess the risks associated with a PRA portfolio of 60 percent stocks and 40 percent bonds. We study the risks to retirees in the transition to a completely investment-based system and in the final post-transition economy. The same mix of assets is used to finance the variable annuities after retirement. We find that the basic PRA saving path that is satisfactory in the absence of uncertainty begins to cause potential risks of low benefits 
to those who retire in 2050 and after. Although the median level of benefits for these cohorts is above the level of benefits projected for the pure PAYGO system under current law (the "benchmark" benefits), there is a 10 percent chance that the combination of PAYGO and PRA benefits will be less than 50 percent of the benchmark.

The risk of relatively low benefits can be reduced substantially by increasing the PRA saving rate for the younger cohorts of workers. For example, with a PRA saving rate that starts at 8 percent of taxable earnings and rises to 9.25 percent of taxable earnings, the cohort that is 30 years old at the time that the transition begins would have only a 10 percent chance of receiving combined benefits of less than 82 percent of the benchmark and only a 5 percent chance that those benefits will be less than 68 percent of the benchmark. Among the 21 year olds in 2000, however, the historic experience implies that there is still a small probability that retirement benefits could be substantially less than the benchmark.

We therefore explore an alternative way to reduce the risk to retirees by a system of conditional intergenerational transfers, i.e., payments from the taxpayers to retirees whose combined benefits (i.e., PAYGO plus PRA) are less than the benchmark level. We assess the probability distribution of the taxes required to finance these transfers. After netting out the incremental corporate tax receipts (i.e., the corporate tax payments on the increased size of the corporate sector capital that results from the PRA saving), we find that even in 2070 (when the risk is greatest) there is only a 20 percent probability of needing any net funds to finance the transfer to retirees. Even when such additional net financing is needed in 2070, there is only a 5 percent chance that the required net transfer would exceed 6 percent of earnings. Thus even with the PRA saving of 4.25 percent of earnings, the taxpayers would have a total burden $(10.25$ 
percent) that was only slightly more than half of the payroll tax that would be required in a pure PAYGO system while the retirees would have at least as much retirement income as they would under the pure PAYGO system.

Finally, we consider the transition to a mixed system that maintains the 12.4 percent payroll tax to finance PAYGO benefits and adds a 2.3 percent saving rate into Personal Retirement Accounts. The high level of PAYGO benefits in this mixed system substantially reduces the risk to retirees. This risk can be completely eliminated by a government guarantee financed by a combination of additional taxes and the incremental corporate tax revenue that results from the PRA savings. We show that the extra risk to taxpayers in providing this guarantee is very small.

Cambridge, MA

January 1999

Revised February 1999 


\section{References}

Board of Trustees, The 1998 Annual Report of the Social Security Trustees, (1998),

Washington, DC.

M. Boskin, et. al. "Social Security: A financial appraisal across and within generations,” National Tax Journal, (1987), 40(1), pp 19-34.

Feldstein, Martin and A. Samwick. "The Economics of Prefunding Social Security and Medicare Benefits, NBER Macroeconomics Annual 1997, (1997), The MIT Press, Cambridge, MA, pp 115-147.

Feldstein, Martin and A. Samwick. "The Transition Path in Privatizing Social Security, in M. Feldstein (ed.), Privatizing Social Security, (Chicago: University of Chicago Press), (1998a), pp 215-260.

Feldstein, Martin and A. Samwick. "Potential Effects of Two Percent Personal Retirement Accounts, Tax Notes, Vol. 79, No. 5, May (1998b), pp 615-620.

Feldstein, Martin and E. Ranguelova. "Individual Risk and Intergenerational Risk Sharing in an Investment-Based Social Security System,” (1998), NBER Working Paper No. 6839.

Feldstein, Martin and E. Ranguelova. "The Economics of Bequests in Pensions and Social Security," NBER Working Paper, forthcoming (1999).

Feldstein, Martin, L. Dicks-Mireaux and J. Poterba. "The Effective Tax Rate Return and the Pretax Rate of Return, Journal of Public Economics, 21(2), July (1983), pp 129-158. 
Kocherlakota, N. “The Equity Premium Puzzle: It's Still a Puzzle,” Journal of Economic

Literature, Volume 34, (1996), pp 42-71.

McHale, John. “The Risk of Social Security Benefit Rule Changes: Some International Evidence," in John Campbell and Martin Feldstein (eds.), Risk Aspects of Social Security $\underline{\text { Reform, }}$ this volume.

Mehra R. And E. Prescott. "The Equity Premium Puzzle," The Journal of Monetary Economics, Volume 15, (1985), pp 145-161.

Poterba, James. “The Rate of Return to Corporate Capital and Factor Shares,” NBER Working Paper No. 6263, (1997).

Smetters, Kent. “Arbitrage Pricing of Unfunded Benefit Guarantees: Rationale and Computations," in John Campbell and Martin Feldstein, Risk Aspects of Social Security $\underline{\text { Reform, }}$ this volume. 